\title{
Interleukin-1 as a Common Denominator from Autoinflammatory to Autoimmune Disorders: Premises, Perils, and Perspectives
}

\author{
Giuseppe Lopalco, ${ }^{1}$ Luca Cantarini, ${ }^{2}$ Antonio Vitale, ${ }^{2}$ \\ Florenzo Iannone, ${ }^{1}$ Maria Grazia Anelli, ${ }^{1}$ Laura Andreozzi, ${ }^{3}$ Giovanni Lapadula, ${ }^{1}$ \\ Mauro Galeazzi, ${ }^{2}$ and Donato Rigante ${ }^{3}$ \\ ${ }^{1}$ Interdisciplinary Department of Medicine, University of Bari, Piazza Giulio Cesare 11, 70124 Bari, Italy \\ ${ }^{2}$ Research Center of Systemic Autoimmune and Autoinflammatory Diseases, University of Siena, Viale Bracci 1, 53100 Siena, Italy \\ ${ }^{3}$ Institute of Pediatrics, Università Cattolica del Sacro Cuore, Largo Agostino Gemelli 8, 00168 Rome, Italy
}

Correspondence should be addressed to Luca Cantarini; cantariniluca@hotmail.com

Received 22 October 2014; Accepted 25 December 2014

Academic Editor: Pham My-Chan Dang

Copyright (C) 2015 Giuseppe Lopalco et al. This is an open access article distributed under the Creative Commons Attribution License, which permits unrestricted use, distribution, and reproduction in any medium, provided the original work is properly cited.

\begin{abstract}
A complex web of dynamic relationships between innate and adaptive immunity is now evident for many autoinflammatory and autoimmune disorders, the first deriving from abnormal activation of innate immune system without any conventional danger triggers and the latter from self-/non-self-discrimination loss of tolerance, and systemic inflammation. Due to clinical and pathophysiologic similarities giving a crucial role to the multifunctional cytokine interleukin-1, the concept of autoinflammation has been expanded to include nonhereditary collagen-like diseases, idiopathic inflammatory diseases, and metabolic diseases. As more patients are reported to have clinical features of autoinflammation and autoimmunity, the boundary between these two pathologic ends is becoming blurred. An overview of monogenic autoinflammatory disorders, PFAPA syndrome, rheumatoid arthritis, type 2 diabetes mellitus, uveitis, pericarditis, Behçet's disease, gout, Sjögren's syndrome, interstitial lung diseases, and Still's disease is presented to highlight the fundamental points that interleukin-1 displays in the cryptic interplay between innate and adaptive immune systems.
\end{abstract}

\section{Introduction}

Autoinflammatory and autoimmune diseases share many characteristics, starting with the prefix "auto" to define a pathological process directed against the self: they are systemic diseases, frequently involving multiple organs; both include monogenic and polygenic diseases, and both are characterized by immune system overactivity. However, the specific effectors of these disorders diverge, as the innate immune system directly causes tissue inflammation in the first, whereas dysregulation of both innate and adaptive immunity is operative in the latter. Mutations in the inflammasomerelated genes have been associated with autoinflammation, and the role of this multiprotein-complex has been postulated also in organ-specific autoimmunity, since a wide spectrum of endogenous danger signals can activate inflammasome products, including interleukin-1 $\beta$ (IL- $1 \beta$ ), and trigger adaptive immunity pathways.

Over the last decade, genome-wide association studies, which use single-nucleotide polymorphism arrays to identify genetic variants with pathogenetic effects in large patient populations, have been conducted for many autoimmune diseases, and new techniques such as high-throughput proteomics and exome sequencing are disclosing novel key-regulators of both immune tolerance and IL-1 $\beta$ biosynthesis.

The identification of novel genes and pathways driving human inflammatory diseases proceeds at an accelerated rhythm: so, what do we know for now? 


\section{Monogenic Autoinflammatory Disorders}

The growing progress on cellular and molecular biology has revealed that an impaired control of innate immune system generates the so-called autoinflammatory disorders (AIDs), a group of heritable diseases characterized by unprovoked attacks of systemic inflammation in the absence of autoantibodies and autoreactive $\mathrm{T}$ cells $[1,2]$. After the discovery of the familial Mediterranean fever-causing gene in 1997, we have witnessed an exciting revolution in the classification of monogenic AIDs with different genetic grounds and in our understanding of intrinsic mechanisms of inflammation. The unifying pathogenetic mechanism of AIDs relies in a lacking regulation of the inflammasome which leads to overproduction of proinflammatory cytokines, especially IL- $1 \beta$ [3]. The family of AIDs (briefly listed in Table 1) includes hereditary periodic fever syndromes and pyogenic and granulomatous disorders, all characterized by recurrent fever attacks accompanied by increase of acute-phase reactants and several overlapping clinical features, that is, rash, serositis, or arthritides usually starting in childhood [4-14]. The development of systemic amyloidosis, due to the deposition of a cleavage product, serum amyloid-A, one of the acute reactants produced during disease flares, is the deadly longterm complication of AIDs [15-17]. Since IL- $1 \beta$ plays a pivotal role in the pathogenesis of most AIDs, monotherapy blocking IL-1 activity results in a sustained reduction of disease severity, regardless of whether the therapeutic agent is anakinra, canakinumab, or rilonacept [18-21]. A checklist of papers dealing with anti-IL1 agents in AIDs is shown in Table 2, and the latest ongoing clinical trials can be found in Table 3 .

\section{PFAPA Syndrome}

The periodic fever, aphthous stomatitis, pharyngitis, and cervical adenitis (or PFAPA) syndrome is an acquired disorder of unknown etiology characterized by periodically recurring episodes of high fever accompanied by at least one among aphthous stomatitis, pharyngitis, or cervical lymph node enlargement [129-132]. Disease onset is generally before 5 years, and persistence in adulthood has been described as well [133]. The exact pathogenesis of the syndrome remains enigmatic, though the brilliant response to single doses of corticosteroids [134] has led to the hypothesis that it might be an acquired autoinflammatory disorder with aberrant cytokine expression $[135,136]$. Indeed, at the molecular level, data from Stojanov et al. have highlighted the role of the proinflammatory cytokine IL- $1 \beta$, which was found elevated in PFAPA patients even between inflammatory attacks [137]. Kolly et al. have found an increased release of IL- $1 \beta$ from stimulated peripheral blood mononuclear cells of children with PFAPA syndrome during febrile episodes. Moreover, approximately $20 \%$ of them have been identified as carrying NLRP3 gene variants, strengthening the hypothesis that inflammasome-related genes might be involved and activated in this condition [138]. A further proof for the role of IL$1 \beta$ derives from clinical responsiveness to IL- $1 \beta$ inhibition: a small uncontrolled study has suggested that treatment with anakinra reduces the duration of acute flares in PFAPA patients [139], and an adult case of PFAPA syndrome refractory to conventional therapy who was responsive to anakinra has also been reported [140]. Since no completely satisfactory treatment options exist for PFAPA syndrome, IL-1 inhibition should be considered in the corticosteroid-resistant cases, especially if adults.

\section{Rheumatoid Arthritis}

A host of proinflammatory cytokines, namely, tumor necrosis factor (TNF- $\alpha$ ), IL-1 $\beta$, and IL-6, are involved in the pathogenesis of rheumatoid arthritis (RA) and are crucial to determine progression of chronic joint inflammation and concomitant bone erosion [141-143]. Serum and synovial concentrations of IL- $1 \beta$ have been found higher in patients with active RA than those in remission $[144,145]$. Furthermore, several studies have shown that IL-1 $\beta$ induces the expression of different proteolytic enzymes, such as the metalloproteinases collagenase and elastase, resulting in destruction of the cartilaginous tissue. On this basis the understanding of RA pathophysiological mechanisms has clarified the role of IL- $1 \beta$ and led to the identification of new potential targets for biological therapy. In this regard anakinra, alone or in combination with methotrexate, has been evaluated in several controlled studies of patients with RA, revealing both decreased disease activity and decreased radiological progression of joint damage in the short term [146-166]. However, even though promising, anakinra seems less effective than other biologic agents in RA, like TNF- $\alpha$ inhibitors [167-170]. A phase II dose-finding study has investigated the favorable response of canakinumab in patients with active RA despite ongoing therapy at stable doses of methotrexate [171]. Integrated analysis from 37 phases II-III studies describing over 13.000 patients with RA showed that there was only a low probability that canakinumab would be better than the most effective current treatments [172].

\section{Type 2 Diabetes Mellitus}

Activation of the innate immune system has been shown relevant in the pathogenesis of type 2 diabetes mellitus (T2DM) [173], and caspase-1 dependent IL-1 production has been demonstrated in macrophages isolated from fat tissue of patients with T2DM [174]. High serum concentrations of glucose lead to increased IL- $1 \beta$ production in human $\beta$ cells, which is followed by NF-kB activation and Fas signalling upregulation, inducing $\beta$-cell apoptosis [175-177]. In addition, other authors have found that oligomers of islet amyloid polypeptide, a protein deposited in the pancreas of patients with T2DM, might trigger NLRP3 inflammasome, enhancing mature IL- $1 \beta$ production and resulting in progressive decrease in $\beta$-cell number, followed by insulin resistance [178-181]. Based on the hypothetic role of IL-1 $\beta$ in the pathogenesis of T2DM, several studies were performed to prove that IL-1 blockade improved $\beta$-cell function and glycemic control. In this regard a double-blind clinical trial involving 70 patients with T2DM revealed that anakinra administration 


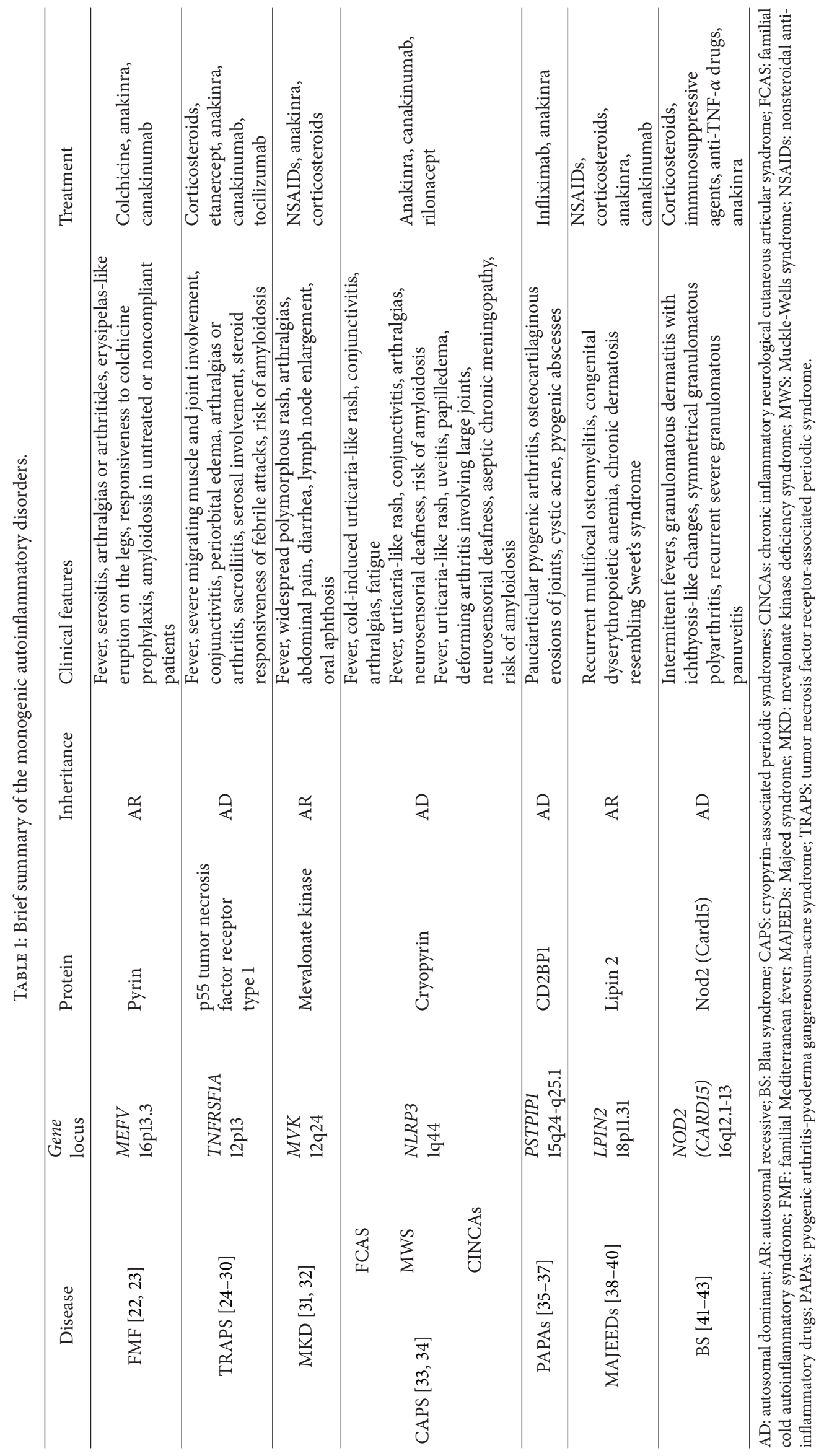


TABLE 2: Overview of the medical literature regarding anti-interleukin-1 therapies in the monogenic autoinflammatory disorders.

\begin{tabular}{lccccccc}
\hline & FMF & TRAPS & MKD & CAPS & PAPAs & MAJEEDs & BS \\
\hline Anakinra & {$[44-58]$} & $\begin{array}{c}{[59]} \\
{[60-64]}\end{array}$ & {$[65-72]$} & $\begin{array}{c}{[73]} \\
{[74-94]}\end{array}$ & {$[95-100]$} & {$[38]$} & {$[101,102]$} \\
\hline Canakinumab & {$[46,50]$} & {$[105-107]$} & {$[68]$} & {$[93,94,108-116]$} & {$[117]$} & {$[38]$} & {$[118]$} \\
\hline Rilonacept & {$[58,103,104]$} & {$[50]$} & & {$[122-128]$} & & \\
\hline
\end{tabular}

BS: Blau syndrome; CAPS: cryopyrin-associated periodic syndromes; FMF: familial Mediterranean fever; MAJEEDs: Majeed syndrome; MKD: mevalonate kinase deficiency syndrome; PAPAs: pyogenic arthritis-pyoderma gangrenosum-acne syndrome; TRAPS: tumor necrosis factor receptor-associated periodic syndrome.

improves beta-cell secretory function: moreover, the beneficial effects on insulin production and systemic proinflammatory parameters were prolonged over time, even after anakinra cessation $[182,183]$. Convincing evidence derives also from the positive effects on HbAlc levels of a single dose of canakinumab in T2DM [184-186]. A large phase III clinical trial CANTOS (Canakinumab Anti-inflammatory Thrombosis Outcomes Study) is currently recruiting participants to assess whether canakinumab may increase insulin secretion and insulin sensitivity in patients with T2DM (ClinicalTrials.gov NCT01327846). Gevokizumab has also proven to be useful in improving HbAlc [187-190]. Several clinical trials are in progress to determine whether gevokizumab might improve glycemic control in subjects with T2DM treated or not with metformin (ClinicalTrials.gov NCT01144975, NCT01066715, NCT00513214). Despite these encouraging results, further studies are needed to consider anti-IL1 agents as new therapeutic instruments for treating T2DM and probably a wider range of metabolic disturbances.

\section{Uveitis}

This sporadic disease has a baffling etiology and is the most frequent extra-articular sign of different systemic autoimmune rheumatologic disorders, such as oligoarticular variant of juvenile idiopathic arthritis, seronegative spondyloarthritis, and Behçet's disease [191]. The inflammatory process leading to uveitis is mainly driven by Th17 cells and sustained by intricate sceneries directed by many proinflammatory cytokines, chiefly TNF- $\alpha$ and IL- $\beta$ [192]. In this regard Kitamei et al. have suggested that NF- $\kappa \mathrm{B}$, activated by IL- $1 \beta$, plays a pivotal role in an experimental murine model of autoimmune uveoretinitis: in fact, pyrrolidine dithiocarbamate administration, which inhibits NF- $\kappa \mathrm{B}$ signaling, has ameliorated clinical symptoms and suppressed ocular IL- $1 \beta$ mRNA expression [193]. Lennikov et al. have shown that uveitis improves after inhibition of $\mathrm{I} \kappa \mathrm{B}$ kinase $\beta$ in an animal model of endotoxin-induced uveitis, particularly when the disease is due to IL- $1 \beta$ and TNF- $\alpha$ oversecretion [194]. Several years before other authors had demonstrated that footpad injection of lipopolysaccharide in rats induced elevated mRNA expression of various cytokines, such as TNF- $\alpha$, IL- $1 \beta$, and IL-1 receptor antagonist (IL-1Ra) in the uvea and retina, suggesting that these mediators contribute to the development and recovery of ocular inflammation $[195,196]$. These evidences have also been corroborated by the capability of anakinra to suppress immune-mediated ocular inflammation not only in animal models [197] but also in a patient with Blau syndrome and in a patient with CINCA syndrome $[73,198]$. More recently a 4-year-old boy diagnosed with early onset sarcoidosis and presenting with refractory severe panuveitis has experienced a rapid remission of uveitis and normalization of most gene expression profiles following canakinumab administration [118]. In addition, after the results of the previous study conducted by Gül et al. on Behçet's disease-resistant uveitis [199], three multicenter phase III clinical trials are ongoing to test safety and efficacy of gevokizumab in the treatment of active noninfectious uveitis (ClinicalTrials.gov NCT01684345), quiescent noninfectious uveitis (ClinicalTrials.gov NCT01747538), and Behçet's disease-associated uveitis (ClinicalTrials.gov NCT01965145). In the end, a phase II clinical trial is also being conducted with gevokizumab in patients with active scleritis (ClinicalTrials.gov NCT01835132).

\section{Pericarditis}

Acute pericarditis may be the first manifestation of an underlying systemic disease [200-203]. Although a specific exact etiology may be identified, its cause remains obscure in up to $85 \%$ of patients. Idiopathic recurrent acute pericarditis (IRAP) is a troubling complication of acute pericarditis, occurring in approximately $30 \%$ of cases [204]. Recently, considering clinical and laboratory features of IRAP (absence of autoantibodies or self-antigen-specific T lymphocytes) [205-208] and the growing evidence about IRAP favourable response to IL-1 inhibition, it has been hypothesized that this condition can be included in the group of AIDs [209-211]. However, IRAP may occur in the framework of two peculiar AIDs, familial Mediterranean fever (FMF) and TNF receptorassociated periodic syndrome (TRAPS), becoming a diagnostic clue for identifying these disorders [22, 59, 212-214]. IRAP may also be the only clinical TRAPS symptom in patients carrying low-penetrance TNFRSF1A mutations [215-217]. According to some authors this recurrent pericarditis can be considered an example of a multifactorial disorder with overlapping pathogenic mechanisms, both autoinflammatory and autoimmune [218]. On this basis, a multicentre study evaluating the incidence of TRAPS mutations in patients with IRAP has demonstrated that positive family history 


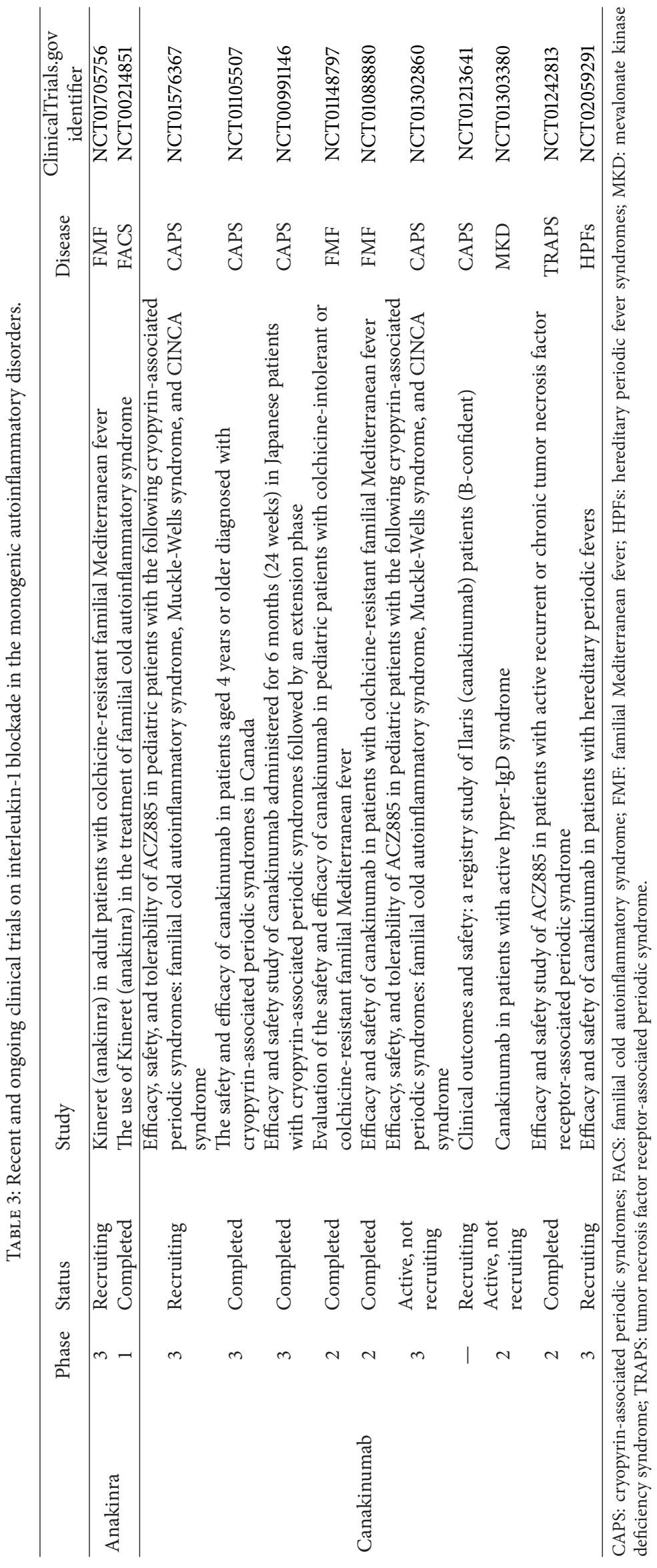


of pericarditis, pericarditis recurrence, failure of treatment with colchicine, and need of immunosuppressive agents were key-elements for suspecting a clinical diagnosis of TRAPS $[219,220]$. Due to these findings, FMF and above all TRAPS should be taken into account in the differential diagnosis of IRAP [221]. Treatment with anakinra has been described as dramatically effective in the control of IRAP, even the corticosteroid-dependent forms of IRAP or those resistant to conventional therapies [210, 211, 222, 223]. Additional data derive from the study of 15 young patients with IRAP performed by Finetti et al., who evaluated long-term use of anakinra: after a median follow-up of 39 months a 95\% reduction of flares was observed, and patients experienced a persistent disease control [209]. More recently Lazaros et al. have confirmed that anakinra is highly effective also in adults with IRAP [224]. A phase IV study designed to demonstrate the efficacy of anakinra in patients with IRAP is actually ongoing (ClinicalTrials.gov NCT02219828), but there are no data about treatment with rilonacept, canakinumab, and gevokizumab.

\section{Behçet's Disease}

The pathogenesis of Behçet's disease (BD) is still largely unknown, and continuous efforts are in progress to characterize its biologic background, suggesting that the disease may lie at the crossroad between autoinflammatory and autoimmune syndromes $[1,225]$. The central role of innate immunity in its pathogenesis has been suggested not only by the increased levels of IL-1 in serum [226] and synovial fluid [227] of $\mathrm{BD}$ patients but also by the beneficial effects obtained with IL-1 inhibition [228]. In addition, the time of disease onset has been correlated with IL-1 gene specific single nucleotide polymorphisms $[229,230]$. Recently Castrichini et al. have observed an increased expression of the P2X7 receptor, a nucleotide-gated ion channel, in $\mathrm{BD}$ monocytes, acting in the promotion of IL-1 $\beta$ release [231]. With regard to therapy, the efficacy of anakinra on various BD manifestations has been well documented in some surveys and several case reports, albeit with variable duration of response [232-236]. A pilot study is ongoing to test whether anakinra given at a daily dose of $100 \mathrm{mg}$ with a dose escalation up to $200 \mathrm{mg} /$ day might control all BD manifestations (ClinicalTrials.gov NCT01441076). The favorable response to anti-IL-1 agents has been also confirmed in three adult BD patients who received canakinumab (150 mg every 6 weeks) as monotherapy [237] and in other two cases $[228,238]$. Table 4 shows a list of papers dealing with IL-1 blockade in BD. Additional convincing evidence for a possible role of IL-1 $\beta$ in BD emerges from a trial with the monoclonal anti-IL-1 $\beta$ antibody gevokizumab, which has proven to be effective in both uveitis and retinal vasculitis, leading to complete resolution of intraocular inflammation [199]. These findings have represented an important aspect in the management of $\mathrm{BD}$, revealing that IL-1 inhibition can be indicated in the treatment of the most severe ocular manifestations, especially if unresponsive to immunosuppressant drugs and other biologicals [239-241].

\section{Gout and Chondrocalcinosis}

Proinflammatory cytokines have a nodal role in orchestrating the body reaction to monosodium urate (MSU) and calcium pyrophosphate dihydrate crystals: recent attention has been focused on the role of IL-1 [242]. Experimental models have suggested that crystals engage the caspase-1-activating NLRP3 inflammasome, resulting in the production of bioactive IL-1 $\beta$ [243]. Further evidence for the proposed role of IL$1 \beta$ in the pathogenesis of gout is shown by the study of Chen et al., in which they demonstrated that IL- $1 \beta$ receptor-deficient mice were not susceptible to MSU-induced inflammation [244]. Other authors have also assessed that activation of the P2X7R-mediated signalling pathway by MSU crystals leads to enhanced NLRP3 inflammasome activity and IL$1 \beta$ oversecretion at the onset of an acute gouty attack [245]. Interestingly, Owyang et al. have reported that gevokizumab was able to reduce acute inflammation in a mouse model, blocking MSU crystal-induced peritonitis [246]. Further proofs of the concept that IL-1 is clearly involved derive from the favorable results obtained with anakinra in an open-label study and several gout-related case reports [247-252]. In line with these findings, Vitale et al. have reported three patients with chronic tophaceous gout unresponsive to standard therapy, in whom anakinra led to remarkable amelioration of joint symptoms within 24 hours. Interestingly, patients were also affected by T2DM and, along with amelioration of joint symptoms, they also experienced a marked improvement in the glycemic control during anakinra treatment [253]. Also canakinumab and rilonacept have proven their efficacy on a broad sample of patients with crystal-induced arthritis [254261], showing a superior therapeutic effect in comparison with corticosteroids. A phase III study testing efficacy of canakinumab in preventing gout relapses is now ongoing for patients with colchicine intolerance (ClinicalTrials.gov NCT01362608). As a result, anti-IL-1 agents should be taken into consideration for both patients affected with unresponsive gouty arthritis and those presenting with dysmetabolic comorbidities.

\section{Sjogren's Syndrome}

This autoimmune disorder is characterized by infiltration of mononuclear cells in the salivary and lacrimal glands, leading to dryness of both mouth and eyes. Although pathogenesis is not completely understood, several studies focusing on cytokine profile that may contribute to the pathological scenery of this disease $[262,263]$ have found an increased concentration of IL-1 in the salivary fluid and peripheral blood of patients with Sjogren's syndrome (SS), indicating that IL-1 works as a pivotal regulator in the development of local and systemic manifestations [264, 265]. Functional consequences of IL1 and low levels of IL-1Ra in the saliva remain unclear. In this regard Dubost et al. have suggested that the salivary IL$1 /$ IL-Ra imbalance may promote inflammatory lesions in the mouth [266], while Solomon et al. have shown that patients with SS produce higher concentration of IL- $1 \alpha$ and IL-1 $\beta$ in the tears [262]. In addition, IL-1 expression in ocular epithelial cells has been correlated with keratinizing squamous 


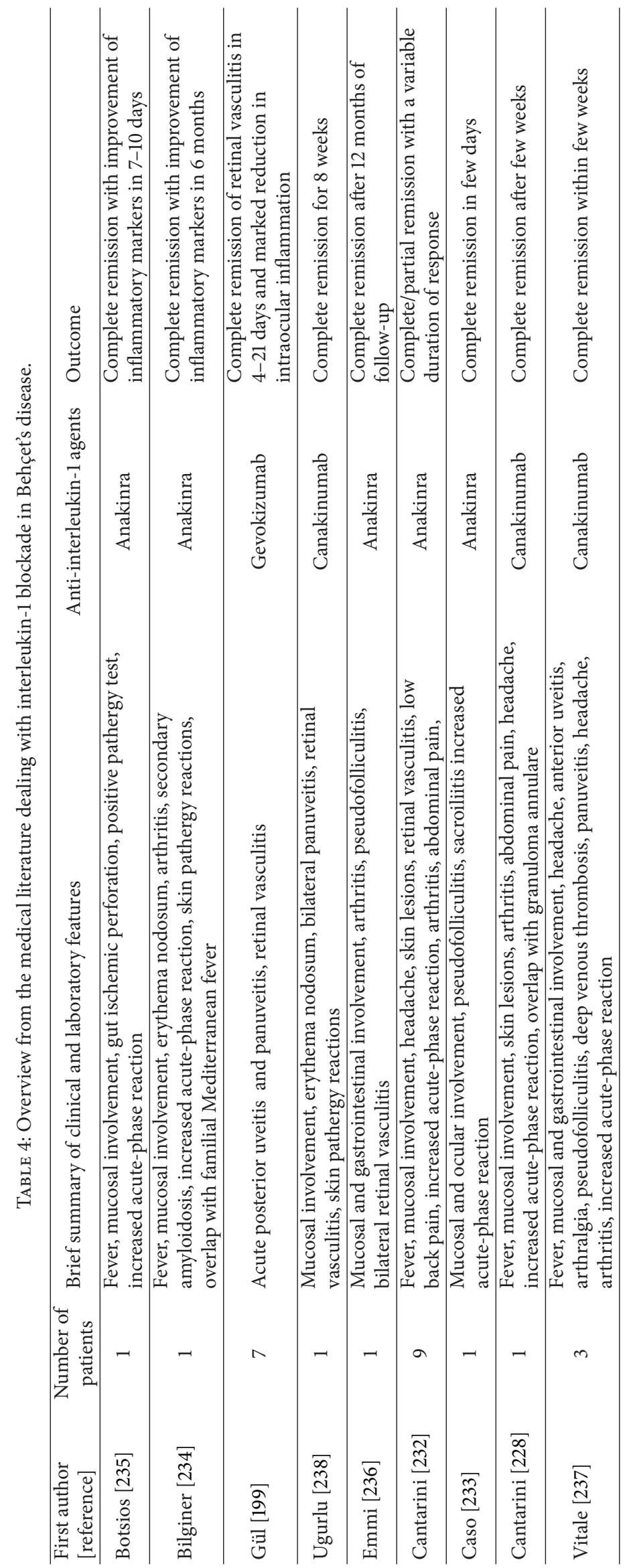


metaplasia, a condition resulting from uncontrolled ocular inflammation [267]. Some authors have also found that IL$1 \beta$ is involved in the destruction of salivary and lacrimal glands [268]: in fact, IL-1 $\beta$ may have a proteolytic activity, leading to acinar and ductal structure disruption in salivary glands of patients with SS [263]. Since acinar cells, duct cells, and blood vessels of the lacrimal glands are innervated by parasympathetic and sympathetic nervous system, several reports have shown that exogenously added IL-1 might inhibit neurotransmitter release [269-271]. Additional data substantiating the crucial role of innate immunity in SS derive from studies on nonobese autoimmune-prone mice. Bulosan et al. have investigated the potential involvement of inflammatory caspases, revealing a concurrent upregulation of caspase-11 in macrophages [272]. Moreover, the presence of the purinergic $\mathrm{P} 2 \mathrm{X} 7$ receptor, an ATP-gated ion channel, in the salivary glands, would be capable of determining NLRP3 inflammasome activation, leading to the release of mature IL-1 $\beta$ and IL-18 [273-275]. Since IL-1 seems to be directly involved in the pathogenesis of SS, there might be a rationale for using anti-IL-1 agents as a potential treatment [276]. In light of this evidence, a randomized double-blind placebo-controlled trial has indicated that IL-1 inhibition with anakinra is able to influence favorably fatigue in patients with SS [277]. More recently, data from a prospective doubleblind randomized trial have also demonstrated that targeting IL-1 by topical application of anakinra is effective in reducing dry eye disease-related symptoms and corneal epitheliopathy [278].

\section{Interstitial Lung Diseases}

Chronic interstitial lung diseases (ILDs), characterized by diffuse lung interstitial wall inflammation, often result in severe pulmonary fibrosis and impaired gas exchange [279]. Alveolar macrophages are involved in various pulmonary inflammatory processes and can constitutively release IL-1, probably due to various exogenous and endogenous stimuli [280]. However, their activity is limited by the presence of IL-1 inhibitory factors secreted from the same macrophages [281]. On this basis, an imbalance between the release of IL-1 and its inhibitor may evoke an inflammatory state [282]. Several studies have revealed the presence of IL- $1 \beta$ in the chronically inflamed lung tissues undergoing fibrogenesis, suggesting a causative link between IL-1 and fibrosis [283$285]$. Through IL-1 $\beta$ overexpression, induced by intratracheal administration of adenoviral genes, Kolb et al. have caused an acute pulmonary inflammation with severe progressive tissue fibrosis in an animal model [286]; they also found that IL$1 \beta$ led to increased concentrations of growth factors in the bronchoalveolar lavage fluid [287]. Interestingly, IL-1 antagonists have been successfully used to block fibrosis in murine models of ILDs [288, 289]. A genetic variability in the ILIRN gene, encoding the physiological IL-1Ra, may contribute to the pathogenesis of idiopathic pulmonary fibrosis [290, 291]. Other authors have suggested that NLRP3 inflammasome is involved in the early inflammatory process of pneumoconiosis and systemic sclerosis [292, 293]. In this regard a phase
I/II study is ongoing to test the effect of the IL-1 inhibitor rilonacept on skin gene expression of patients with systemic sclerosis (ClinicalTrials.gov NCT01538719). Moreover, a case of antisynthetase syndrome clinically characterized by progressive and diffuse interstitial lung disease and myositis responding to anakinra has been reported [294], while another one lost its efficacy on lung disease manifestations [295]. Although IL-1 $\beta$ might be considered a valid target for treatment of ILDs, further studies are required to fully explore and define its exact role in the pathogenesis of ILDs.

\section{Still's Disease}

This rare inflammatory disorder of undisclosed etiology is characterized by fever, rash, arthritis, and prominent neutrophilia, accompanied by high C-reactive protein and ferritin levels [296]. Similarly to what we observe in the monogenic AIDs, the main proinflammatory cytokine increased in adult onset Still's disease (AOSD) is IL-1 $\beta$ [297, 298]. Macrophage activation syndrome has been rarely reported in the course of AOSD, but mortality in adults is far higher than that for children with systemic-onset juvenile idiopathic arthritis [299]. Convincing evidence about IL-1 involvement in this disorder derives from the study by Pascual et al., reporting that peripheral blood mononuclear cells of healthy subjects incubated with sera from patients with systemiconset juvenile idiopathic arthritis secreted large amounts of IL- $1 \beta$ and led to increased expression of innate immunity genes [300]. Benefits obtained with IL-1 antagonists have also reinvigorated the concept that IL- $1 \beta$ is largely implicated in the pathological scenery of AOSD. Notably, anakinra as monotherapy has proven to be highly effective in patients refractory to conventional treatments (corticosteroids and methotrexate). These findings rely not only on single case reports and small case series [301-321] but also on large numbers of subjects: a study of 25 patients with active multiresistant AOSD reported a complete resolution of clinical activity in $84 \%$ of cases and normalization of laboratory markers in $80 \%$ [322]. Moreover, an open randomized multicentre study has enrolled 22 patients with AOSD, demonstrating that anakinra brings about remission in the refractory forms of the disease [323]. A recent retrospective study carried out to assess long-term efficacy of anakinra in 28 patients has shown a complete remission in $57 \%$ of them after a mean follow-up time of 23 months [324]. Also canakinumab and rilonacept have proven the efficacy of IL-1 inhibition in AOSD. In this regard Henderson et al. have investigated treatment with rilonacept in a small sample of patients, observing a good clinical response [325]. More recently the successful use of rilonacept in the management of three patients with refractory AOSD [326] as well as the effectiveness of canakinumab in curbing AOSD manifestations has been reported [327, 328]. A phase II study is now ongoing to assess whether canakinumab may confirm its promising effects in the decrease of disease activity (ClinicalTrials.gov NCT02204293). 


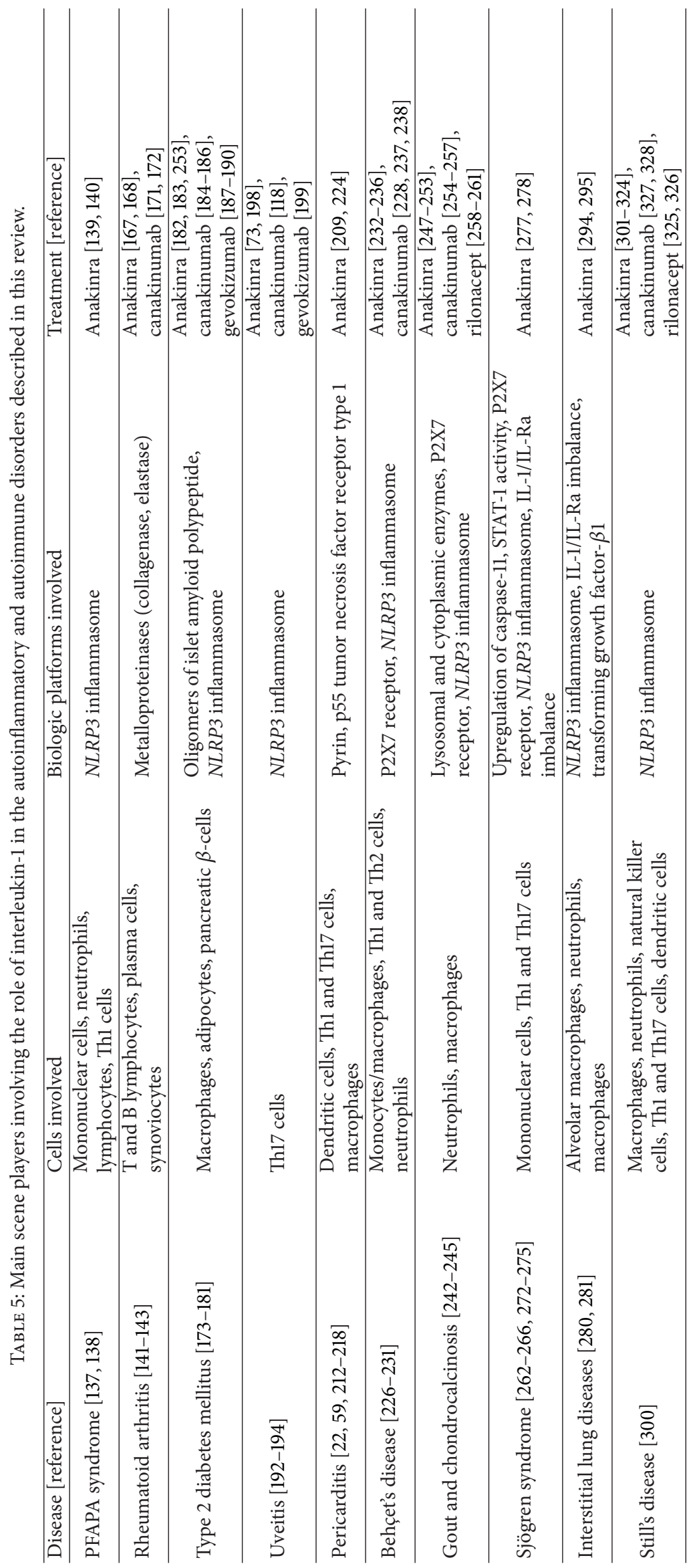




\section{Conclusions}

From a mere pathogenic point of view most autoinflammatory and autoimmune diseases share the chronic aberrant activation of the immune system, which leads to tissue inflammation and/or tissue damage of varying magnitude and extent in genetically predisposed individuals. The specific effectors of inflammation and damage are different in the two groups of disorders, respectively, the innate and adaptive immunity branches, even if in the last decade we began to recognize the involvement of autoinflammatory circuits in many different diseases and also those having an autoimmune basis. Certainly, the role of IL-1 on lymphocyte function, favouring the expansion of autoreactive Th1 and Th17 cells or downregulating regulatory $\mathrm{T}$ cells, has not been yet completely elucidated and requires further research to change our way of categorizing an expanding group of inflammatory disorders, even autoimmune diseases. Table 5 recapitulates all cells and the different biologic platforms involved in the various clinical settings driven by IL-1 oversecretion. Unearthing the molecular pathways of autoinflammation and autoimmunity has enlightened our capacity of understanding the human disease, and recent technological breakthroughs have also generated large quantities of novel information specifically in both autoinflammatory and autoimmune diseases at the genetic, transcriptional, proteic, and metabolic levels. The acceleration of clinical trials over the past decades has also included rare diseases, such as AIDs. Studies of such complex disorders and their relationship with IL-1 need to address heterogeneity in the human population, interaction with the environment, and effects of treatments, while a multidisciplinary approach should be ultimately fostered to provide a significant change in the knowledge of these diseases across the scientific community.

\section{Conflict of Interests}

The authors declare that there is no conflict of interests regarding the publication of this paper.

\section{Authors' Contribution}

Giuseppe Lopalco and Luca Cantarini equally contributed to this work.

\section{References}

[1] D. McGonagle and M. F. McDermott, "A proposed classification of the immunological diseases," PLoS Medicine, vol. 3, no. 8, article e297, 2006.

[2] I. Touitou and I. Koné-Paut, "Autoinflammatory diseases," Best Practice and Research: Clinical Rheumatology, vol. 22, no. 5, pp. 811-829, 2008.

[3] D. Rigante, "The fresco of autoinflammatory diseases from the pediatric perspective," Autoimmunity Reviews, vol. 11, no. 5, pp. 348-356, 2012.

[4] L. Cantarini, O. M. Lucherini, F. Iacoponi et al., "Development and preliminary validation of a diagnostic score for identifying patients affected with adult-onset autoinflammatory disorders,"
International Journal of Immunopathology and Pharmacology, vol. 23, no. 4, pp. 1133-1141, 2010.

[5] L. Cantarini, D. Rigante, M. G. Brizi et al., "Clinical and biochemical landmarks in systemic autoinflammatory diseases," Annals of Medicine, vol. 44, no. 7, pp. 664-673, 2012.

[6] L. Cantarini, F. Iacoponi, O. M. Lucherini et al., "Validation of a diagnostic score for the diagnosis of autoinflammatory diseases in adults," International Journal of Immunopathology and Pharmacology, vol. 24, no. 3, pp. 695-702, 2011.

[7] I. Muscari, F. Iacoponi, L. Cantarini et al., "The diagnostic evaluation of patients with potential adult-onset autoinflammatory disorders: our experience and review of the literature," Autoimmunity Reviews, vol. 12, no. 1, pp. 10-13, 2012.

[8] L. Cantarini, A. Vitale, O. M. Lucherini et al., "Childhood versus adulthood-onset autoinflammatory disorders: myths and truths intertwined," Reumatismo, vol. 65, no. 2, pp. 55-62, 2013.

[9] D. Rigante, A. Vitale, O. M. Lucherini, and L. Cantarini, “The hereditary autoinflammatory disorders uncovered," Autoimmunity Reviews, vol. 13, no. 9, pp. 892-900, 2014.

[10] D. Rigante, G. Lopalco, A. Vitale et al., "Untangling the web of systemic autoinflammatory diseases," Mediators of Inflammation, vol. 2014, Article ID 948154, 15 pages, 2014.

[11] L. Cantarini, A. Vitale, O. M. Lucherini et al., "The labyrinth of autoinflammatory disorders: a snapshot on the activity of a third-level center in Italy," Clinical Rheumatology, 2014.

[12] F. Caso, D. Rigante, A. Vitale et al., "Monogenic autoinflammatory syndromes: state of the art on genetic, clinical, and therapeutic issues," International Journal of Rheumatology, vol. 2013, Article ID 513782, 15 pages, 2013.

[13] F. Caso, L. Cantarini, O. M. Lucherini et al., "Working the endless puzzle of hereditary autoinflammatory disorders," Modern Rheumatology, vol. 24, no. 3, pp. 381-389, 2014.

[14] A. Vitale, D. Rigante, M. C. Maggio et al., "Rare NLRP12 variants associated with the NLRP12-autoinflammatory disorder phenotype: an Italian case series," Clinical and Experimental Rheumatology, vol. 31, no. 3, supplement 77, pp. 155-156, 2013.

[15] D. Rigante, I. la Torraca, V. Ansuini, A. Compagnone, A. Salli, and A. Stabile, "The multi-face expression of familial mediterranean fever in the child," European Review for Medical and Pharmacological Sciences, vol. 10, no. 4, pp. 163-171, 2006.

[16] D. Rigante, B. Frediani, M. Galeazzi, and L. Cantarini, "From the mediterranean to the sea of Japan: the transcontinental odyssey of autoinflammatory diseases," BioMed Research International, vol. 2013, Article ID 485103, 8 pages, 2013.

[17] T. Lane, J. M. Loeffler, D. M. Rowczenio et al., "AA amyloidosis complicating the hereditary periodic fever syndromes," Arthritis \& Rheumatism, vol. 65, no. 4, pp. 1116-1121, 2013.

[18] D. Rigante, V. Ansuini, M. Caldarelli, B. Bertoni, I. la Torraca, and A. Stabile, "Hydrocephalus in CINCA syndrome treated with anakinra," Child's Nervous System, vol. 22, no. 4, pp. 334337, 2006.

[19] A. Vitale, D. Rigante, O. M. Lucherini et al., "Biological treatments: new weapons in the management of monogenic autoinflammatory disorders," Mediators of Inflammation, vol. 2013, Article ID 939847, 16 pages, 2013.

[20] N. Ter Haar, H. Lachmann, S. Özen et al., "Treatment of autoinflammatory diseases: results from the Eurofever Registry and a literature review," Annals of the Rheumatic Diseases, vol. 72, no. 5, pp. 678-685, 2013.

[21] L. Cantarini, O. M. Lucherini, B. Frediani et al., "Bridging the gap between the clinician and the patient with 
cryopyrin-associated periodic syndromes," International Journal of Immunopathology and Pharmacology, vol. 24, no. 4, pp. 827-836, 2011.

[22] S. Ozen, E. Demirkaya, G. Amaryan et al., "Results from a multicentre international registry of familial Mediterranean fever: impact of environment on the expression of a monogenic disease in children," Annals of the Rheumatic Diseases, vol. 73, pp. 662-667, 2014.

[23] L. Cantarini, P. L. Capecchi, O. M. Lucherini, F. Laghi Pasini, and M. Galeazzi, "Familial Mediterranean fever diagnosed in an elderly patient," Clinical and Experimental Rheumatology, vol. 28, no. 4, supplement 6, p. S91, 2010.

[24] D. Rigante, G. Lopalco, A. Vitale et al., "Key facts and hot spots on tumor necrosis factor receptor-associated periodic syndrome," Clinical Rheumatology, vol. 33, no. 9, pp. 1197-1207, 2014.

[25] H. J. Lachmann, R. Papa, K. Gerhold et al., "The phenotype of TNF receptor-associated autoinflammatory syndrome (TRAPS) at presentation: a series of 158 cases from the Eurofever/EUROTRAPS international registry," Annals of the Rheumatic Diseases, vol. 73, no. 12, pp. 2160-2167, 2014.

[26] F. Magnotti, A. Vitale, D. Rigante et al., "The most recent advances in pathophysiology and management of tumour necrosis factor receptor-associated periodic syndrome (TRAPS): personal experience and literature review," Clinical and Experimental Rheumatology, vol. 31, supplement 77, no. 3, pp. S141S149, 2013.

[27] L. Cantarini, D. Rigante, O. M. Lucherini et al., "Role of etanercept in the treatment of tumor necrosis factor receptorassociated periodic syndrome: personal experience and review of the literature," International Journal of Immunopathology and Pharmacology, vol. 23, no. 3, pp. 701-707, 2010.

[28] L. Cantarini, O. M. Lucherini, R. Cimaz, C. T. Baldari, F. Laghi Pasini, and M. Galeazzi, "Sacroileitis and pericarditis: Atypical presentation of tumour necrosis factor receptor-associated periodic syndrome and response to etanercept therapy," Clinical and Experimental Rheumatology, vol. 28, no. 2, pp. 290-291, 2010.

[29] L. Cantarini, O. M. Lucherini, R. Cimaz et al., "Typical and severe tumor necrosis factor receptor-associated periodic syndrome in the absence of mutations in the TNFRSF1A gene: a case series," Rheumatology International, vol. 32, no. 12, pp. 4015-4018, 2012.

[30] L. Cantarini, O. M. Lucherini, M. Galeazzi et al., "Tumour necrosis factor receptor-associated periodic syndrome caused by a rare mutation in the TNFRSF1A gene, and with excellent response to etanercept treatment," Clinical and Experimental Rheumatology, vol. 27, no. 5, pp. 890-891, 2009.

[31] L. Cantarini, A. Vitale, F. Magnotti et al., "Weekly oral alendronate in mevalonate kinase deficiency," Orphanet Journal of Rare Diseases, vol. 8, no. 1, article 196, 2013.

[32] R. van der Burgh, N. M. ter Haar, M. L. Boes, and J. Frenkel, "Mevalonate kinase deficiency, a metabolic autoinflammatory disease," Clinical Immunology, vol. 147, no. 3, pp. 197-206, 2013.

[33] R. Levy, L. Gérard, J. Kuemmerle-Deschner et al., "Phenotypic and genotypic characteristics of cryopyrin-associated periodic syndrome: a series of 136 patients from the Eurofever Registry," Annals of the Rheumatic Diseases, 2014.

[34] A. Vitale, O. M. Lucherini, M. Galeazzi, B. Frediani, and L. Cantarini, "Long-term clinical course of patients carrying the Q703K mutation in the NLRP3 gene: a case series," Clinical and Experimental Rheumatology, vol. 30, no. 6, pp. 943-946, 2012.
[35] E. J. Smith, F. Allantaz, L. Bennett et al., "Clinical, molecular, and genetic characteristics of PAPA syndrome: a review," Current Genomics, vol. 11, no. 7, pp. 519-527, 2010.

[36] A. P. Demidowich, A. F. Freeman, D. B. Kuhns et al., "Genotype, phenotype, and clinical course in five patients with PAPA syndrome (pyogenic sterile arthritis, pyoderma gangrenosum, and acne)," Arthritis and Rheumatism, vol. 64, no. 6, pp. 20222027, 2012.

[37] B. Tallon and M. Corkill, "Peculiarities of PAPA syndrome," Rheumatology, vol. 45, no. 9, pp. 1140-1143, 2006.

[38] T. Herlin, B. Fiirgaard, M. Bjerre et al., "Efficacy of anti-IL-1 treatment in Majeed syndrome," Annals of the Rheumatic Diseases, vol. 72, no. 3, pp. 410-413, 2013.

[39] H. I. El-Shanti and P. J. Ferguson, "Chronic recurrent multifocal osteomyelitis: a concise review and genetic update," Clinical Orthopaedics and Related Research, vol. 462, pp. 11-19, 2007.

[40] P. J. Ferguson and H. I. El-Shanti, "Autoinflammatory bone disorders," Current Opinion in Rheumatology, vol. 19, no. 5, pp. 492-498, 2007.

[41] F. Caso, L. Costa, D. Rigante et al., "Caveats and truths in genetic, clinical, autoimmune and autoinflammatory issues in Blau syndrome and early onset sarcoidosis," Autoimmunity Reviews, vol. 13, no. 12, pp. 1220-1229, 2014.

[42] F. la Torre, G. Lapadula, L. Cantarini, O. M. Lucherini, and F. Iannone, "Early-onset sarcoidosis caused by a rare CARD15/NOD2 de novo mutation and responsive to infliximab: a case report with long-term follow-up and review of the literature," Clinical Rheumatology, 2014.

[43] P. Sfriso, F. Caso, S. Tognon, P. Galozzi, A. Gava, and L. Punzi, "Blau syndrome, clinical and genetic aspects," Autoimmunity Reviews, vol. 12, no. 1, pp. 44-51, 2012.

[44] K. S. Stojanovic, Y. Delmas, P. U. Torres et al., "Dramatic beneficial effect of interleukin-1 inhibitor treatment in patients with familial Mediterranean fever complicated with amyloidosis and renal failure," Nephrology Dialysis Transplantation, vol. 27, no. 5, pp. 1898-1901, 2012.

[45] C. Moser, G. Pohl, I. Haslinger et al., "Successful treatment of familial Mediterranean fever with anakinra and outcome after renal transplantation," Nephrology Dialysis Transplantation, vol. 24, no. 2, pp. 676-678, 2009.

[46] U. Meinzer, P. Quartier, J.-F. Alexandra, V. Hentgen, F. Retornaz, and I. Koné-Paut, "Interleukin-1 targeting drugs in familial Mediterranean fever: a case series and a review of the literature," Seminars in Arthritis and Rheumatism, vol. 41, no. 2, pp. 265271, 2011.

[47] L. Calligaris, F. Marchetti, A. Tommasini, and A. Ventura, "The efficacy of anakinra in an adolescent with colchicine-resistant familial Mediterranean fever," European Journal of Pediatrics, vol. 167, no. 6, pp. 695-696, 2008.

[48] I. Mitroulis, V. P. Papadopoulos, T. Konstantinidis, and K. Ritis, "Anakinra suppresses familial Mediterranean fever crises in a colchicine-resistant patient," The Netherlands Journal of Medicine, vol. 66, no. 11, pp. 489-491, 2008.

[49] A. D. Petropoulou, M. Robin, G. Socié, and L. Galicier, "Transmission of familial Mediterranean fever mutation after bone marrow transplantation and successful treatment with anakinra," Transplantation, vol. 90, no. 1, pp. 102-103, 2010.

[50] A. Soriano, E. Verecchia, A. Afeltra, R. Landolfi, and R. Manna, "IL-1 $\beta$ biological treatment of familial mediterranean fever," Clinical Reviews in Allergy \& Immunology, vol. 45, no. 1, pp. 117130, 2013. 
[51] C. Estublier, K. S. Stojanovic, J.-F. Bergerot, C. Broussolle, and P. Sève, "Myositis in a patient with familial Mediterranean fever and spondyloarthritis successfully treated with anakinra," Joint Bone Spine, vol. 80, no. 6, pp. 645-649, 2013.

[52] N. Alpay, A. Şumnu, Y. ÇalIśkan, H. Yazıcı, A. Türkmen, and A. Gül, "Efficacy of anakinra treatment in a patient with colchicine-resistant familial Mediterranean fever," Rheumatology International, vol. 32, no. 10, pp. 3277-3279, 2012.

[53] R. Belkhir, L. Moulonguet-Doleris, E. Hachulla, J. Prinseau, A. Baglin, and T. Hanslik, "Treatment of familial mediterranean fever with anakinra," Annals of Internal Medicine, vol. 146, no. 11, pp. 825-826, 2007.

[54] R. Gattringer, H. Lagler, K. B. Gattringer et al., "Anakinra in two adolescent female patients suffering from colchicine-resistant familial Mediterranean fever: effective but risky," European Journal of Clinical Investigation, vol. 37, no. 11, pp. 912-914, 2007.

[55] L. M. Kuijk, A. M. A. P. Govers, W. J. D. Hofhuis, and J. Frenkel, "Effective treatment of a colchicine-resistant familial Mediterranean fever patient with anakinra," Annals of the Rheumatic Diseases, vol. 66, no. 11, pp. 1545-1546, 2007.

[56] S. Özen, Y. Bilginer, N. A. Ayaz, and M. Calguneri, "Antiinterleukin 1 treatment for patients with familial Mediterranean fever resistant to colchicine," The Journal of Rheumatology, vol. 38, no. 3, pp. 516-518, 2011.

[57] R. Roldan, A. M. Ruiz, M. D. Miranda, and E. Collantes, "Anakinra: new therapeutic approach in children with familial Mediterranean fever resistant to colchicine," Joint Bone Spine, vol. 75, no. 4, pp. 504-505, 2008.

[58] O. Akgul, E. Kilic, G. Kilic, and S. Ozgocmen, "Efficacy and safety of biologic treatments in familial Mediterranean fever," The American Journal of the Medical Sciences, vol. 346, no. 2, pp. 137-141, 2013.

[59] L. Cantarini, O. M. Lucherini, R. Cimaz, and M. Galeazzi, "Recurrent pericarditis caused by a rare mutation in the TNFRSF1A gene and with excellent response to anakinra treatment," Clinical and Experimental Rheumatology, vol. 28, no. 5, article 802, 2010.

[60] M. Gattorno, M. A. Pelagatti, A. Meini et al., "Persistent efficacy of anakinra in patients with tumor necrosis factor receptorassociated periodic syndrome," Arthritis \& Rheumatism, vol. 58, no. 5, pp. 1516-1520, 2008.

[61] A. Simon, E. J. Bodar, J. C. H. van der Hilst et al., "Beneficial response to interleukin-1 receptor antagonist in TRAPS," The American Journal of Medicine, vol. 117, no. 3, pp. 208-210, 2004.

[62] K. Sacré, B. Brihaye, O. Lidove et al., "Dramatic improvement following interleukin $1 \beta$ blockade in tumor necrosis factor receptor-1-associated syndrome (TRAPS) resistant to anti-TNF$\alpha$ therapy," Journal of Rheumatology, vol. 35, no. 2, pp. 357-358, 2008.

[63] M. Andrés and E. Pascual, "Anakinra for a refractory case of intermittent hydrarthrosis with a TRAPS-related gene mutation," Annals of the Rheumatic Diseases, vol. 72, no. 1, p. 155, 2013.

[64] O. M. Lucherini, L. Obici, M. Ferracin et al., "First report of circulating microRNAs in tumour necrosis factor receptorassociated periodic syndrome (TRAPS)," PLoS ONE, vol. 8, no. 9, Article ID e73443, 2013.

[65] M. Cailliez, F. Garaix, C. Rousset-Rouvière et al., "Anakinra is safe and effective in controlling hyperimmunoglobulinaemia D syndrome-associated febrile crisis," Journal of Inherited Metabolic Disease, vol. 29, no. 6, p. 763, 2006.
[66] D. Rigante, V. Ansuini, B. Bertoni et al., “Treatment with anakinra in the hyperimmunoglobulinemia D/periodic fever syndrome," Rheumatology International, vol. 27, no. 1, pp. 97-100, 2006.

[67] T. Lequerré, O. Vittecoq, S. Pouplin et al., "Mevalonate kinase deficiency syndrome with structural damage responsive to anakinra," Rheumatology, vol. 46, no. 12, pp. 1860-1862, 2007.

[68] C. Galeotti, U. Meinzer, P. Quartier et al., "Efficacy of interleukin-1-targeting drugs in mevalonate kinase deficiency," Rheumatology, vol. 51, no. 10, pp. 1855-1859, 2012.

[69] E. J. Bodar, L. M. Kuijk, J. P. H. Drenth, J. W. M. van der Meer, A. Simon, and J. Frenkel, "On-demand anakinra treatment is effective in mevalonate kinase deficiency," Annals of the Rheumatic Diseases, vol. 70, no. 12, pp. 2155-2158, 2011.

[70] E. J. Bodar, J. C. H. van der Hilst, J. P. H. Drenth, J. W. M. van der Meer, and A. Simon, "Effect of etanercept and anakinra on inflammatory attacks in the hyper-IgD syndrome: introducing a vaccination provocation model," Netherlands Journal of Medicine, vol. 63, no. 7, pp. 260-264, 2005.

[71] A. R. Gomez, M. L. Couce, J. Garcia-Villoria et al., "Clinical, genetic, and therapeutic diversity in 2 patients with severe mevalonate kinase deficiency," Pediatrics, vol. 129, no. 2, pp. e535-e539, 2012.

[72] H. M. Shendi, D. Walsh, and J. D. M. Edgar, "Etanercept and anakinra can prolong febrile episodes in patients with hyperimmunoglobulin D and periodic fever syndrome," Rheumatology International, vol. 32, no. 1, pp. 249-251, 2012.

[73] S. C. B. Teoh, S. Sharma, A. Hogan, R. Lee, A. V. Ramanan, and A. D. Dick, "Tailoring biological treatment: anakinra treatment of posterior uveitis associated with the CINCA syndrome," British Journal of Ophthalmology, vol. 91, no. 2, pp. 263-264, 2007.

[74] C. M. Hedrich, N. Bruck, D. Paul, M. Gahr, A. Rösen-Wolv, and G. Hahn, “'Mutation negative' familial cold autoinXammatory syndrome (FCAS) in an 8-year-old boy: clinical course and functional studies," Rheumatology International, vol. 32, no. 9, pp. 2629-2636, 2012.

[75] R. Goldbach-Mansky, N. J. Dailey, S. W. Canna et al., "Neonatalonset multisystem inflammatory disease responsive to interleukin-1 $\beta$ inhibition," The New England Journal of Medicine, vol. 355, no. 6, pp. 581-592, 2006.

[76] M. Gattorno, S. Tassi, S. Carta et al., "Pattern of interleukin- $1 \beta$ secretion in response to lipopolysaccharide and ATP before and after interleukin-1 blockade in patients with CIAS1 mutations," Arthritis \& Rheumatism, vol. 56, no. 9, pp. 3138-3148, 2007.

[77] B. Neven, I. Marvillet, C. Terrada et al., "Long-term efficacy of the interleukin-1 receptor antagonist anakinra in ten patients with neonatal-onset multisystem inflammatory disease/chronic infantile neurologic, cutaneous, articular syndrome," Arthritis and Rheumatism, vol. 62, no. 1, pp. 258-267, 2010.

[78] L. Lepore, G. Paloni, R. Caorsi et al., "Follow-up and quality of life of patients with cryopyrin-associated periodic syndromes treated with Anakinra," The Journal of Pediatrics, vol. 157, no. 2, pp. 310.e1-315.e1, 2010.

[79] T. Miyamae, Y. Inaba, G. Nishimura et al., "Effect of anakinra on arthropathy in CINCA/NOMID syndrome," Pediatric Rheumatology, vol. 8, article 9, 2010.

[80] D. J. Lovell, S. L. Bowyer, and A. M. Solinger, "Interleukin-1 blockade by anakinra improves clinical symptoms in patients with neonatal-onset multisystem inflammatory disease," Arthritis \& Rheumatism, vol. 52, no. 4, pp. 1283-1286, 2005. 
[81] P. Aubert, M. Suárez-Fariñas, H. Mitsui et al., "Homeostatic tissue responses in skin biopsies from NOMID patients with constitutive overproduction of IL-1 $\beta$," PLoS ONE, vol. 7, no. 11, Article ID e49408, 2012.

[82] J. E. Balow Jr., J. G. Ryan, J. J. Chae et al., "Microarray-based gene expression profiling in patients with cryopyrin-associated periodic syndromes defines a disease-related signature and IL1-responsive transcripts," Annals of the Rheumatic Diseases, vol. 72, no. 6, pp. 1064-1070, 2013.

[83] C. H. Sibley, N. Plass, J. Snow et al., "Sustained response and prevention of damage progression in patients with neonatalonset multisystem inflammatory disease treated with anakinra: a cohort study to determine three- and five-year outcomes," Arthritis \& Rheumatism, vol. 64, no. 7, pp. 2375-2386, 2012.

[84] P. N. Hawkins, H. J. Lachmann, and M. F. McDermott, "Interleukin-1-receptor antagonist in the Muckle-Wells syndrome," The New England Journal of Medicine, vol. 348, no. 25, pp. 2583-2584, 2003.

[85] M. Rynne, C. Maclean, A. Bybee, M. F. McDermott, and P. Emery, "Hearing improvement in a patient with variant Muckle-Wells syndrome in response to interleukin 1 receptor antagonism," Annals of the Rheumatic Diseases, vol. 65, no. 4, pp. 533-534, 2006.

[86] B. T. Stew, S. J. C. Fishpool, D. Owens, and S. Quine, "MuckleWells syndrome: a treatable cause of congenital sensorineural hearing loss," B-ENT, vol. 9, no. 2, pp. 161-163, 2013.

[87] R. A. Sabroe, C. A. Stokes, L. C. Parker, K. Higgins, L. R. Prince, and I. Sabroe, "Muckle-Wells syndrome without mutation in exon 3 of the NLRP3 gene, identified by evidence of excessive monocyte production of functional interleukin $1 \beta$ and rapid response to anakinra," Clinical and Experimental Dermatology, vol. 38, no. 8, pp. 874-877, 2013.

[88] R. Enríquez, A. E. Sirvent, S. Padilla et al., "Nephrotic syndrome and AA amyloidosis revealing adult-onset cryopyrin-associated periodic syndrome," Renal Failure, vol. 35, no. 5, pp. 738-741, 2013.

[89] J. B. Kuemmerle-Deschner, P. N. Tyrrell, I. Koetter et al., "Efficacy and safety of anakinra therapy in pediatric and adult patients with the autoinflammatory Muckle-Wells syndrome," Arthritis \& Rheumatism, vol. 63, no. 3, pp. 840-849, 2011.

[90] P. N. Hawkins, H. J. Lachmann, E. Aganna, and M. F. McDermott, "Spectrum of clinical Features in Muckle-Wells syndrome and response to anakinra," Arthritis and Rheumatism, vol. 50, no. 2, pp. 607-612, 2004.

[91] S. K. Metyas and H. M. Hoffman, "Anakinra prevents symptoms of familial cold autoinflammatory syndrome and Raynaud's disease," Journal of Rheumatology, vol. 33, no. 10, pp. 2085-2087, 2006.

[92] H. M. Hoffman, S. Rosengren, D. L. Boyle et al., "Prevention of cold-associated acute inflammation in familial cold autoinflammatory syndrome by interleukin-1 receptor antagonist," The Lancet, vol. 364, no. 9447, pp. 1779-1785, 2004.

[93] J. B. Kuemmerle-Deschner, H. Wittkowski, P. N. Tyrrell et al., "Treatment of Muckle-Wells syndrome: analysis of two IL-1blocking regimens," Arthritis Research and Therapy, vol. 15, no. 3, article R64, 2013.

[94] J. B. Kuemmerle-Deschner, P. Lohse, I. Koetter et al., "NLRP3 E311K mutation in a large family with Muckle-Wells syndrome-description of a heterogeneous phenotype and response to treatment," Arthritis Research and Therapy, vol. 13, no. 6, article R196, 2011.
[95] N. Pazyar, A. Feily, and R. Yaghoobi, "An overview of interleukin-1 receptor antagonist, anakinra, in the treatment of cutaneous diseases," Current Clinical Pharmacology, vol. 7, no. 4, pp. 271-275, 2012.

[96] M. Braun-Falco, O. Kovnerystyy, P. Lohse, and T. Ruzicka, "Pyoderma gangrenosum, acne, and suppurative hidradenitis (PASH) - a new autoinflammatory syndrome distinct from PAPA syndrome," Journal of the American Academy of Dermatology, vol. 66, no. 3, pp. 409-415, 2012.

[97] M. Brenner, T. Ruzicka, G. Plewig, P. Thomas, and P. Herzer, "Targeted treatment of pyoderma gangrenosum in PAPA (pyogenic arthritis, pyoderma gangrenosum and acne) syndrome with the recombinant human interleukin-1 receptor antagonist anakinra," British Journal of Dermatology, vol. 161, no. 5, pp. 1199-1201, 2009.

[98] M. P. Dierselhuis, J. Frenkel, N. M. Wulffraat, and J. J. Boelens, "Anakinra for flares of pyogenic arthritis in PAPA syndrome," Rheumatology, vol. 44, no. 3, pp. 406-408, 2005.

[99] M. A. Schellevis, M. Stoffels, E. P. A. H. Hoppenreijs, E. Bodar, A. Simon, and J. W. M. van der Meer, "Variable expression and treatment of PAPA syndrome," Annals of the Rheumatic Diseases, vol. 70, no. 6, pp. 1168-1170, 2011.

[100] N. G. Shoham, M. Centola, E. Mansfield et al., "Pyrin binds the PSTPIP1/CD2BP1 protein, defining familial Mediterranean fever and PAPA syndrome as disorders in the same pathway," Proceedings of the National Academy of Sciences of the United States of America, vol. 100, no. 23, pp. 13501-13506, 2003.

[101] L. Punzi, A. Gava, P. Galozzi, and P. Sfriso, "Miscellaneous noninflammatory musculoskeletal conditions. Blau syndrome.," Best Practice and Research: Clinical Rheumatology, vol. 25, no. 5, pp. 703-714, 2011.

[102] T. M. Martin, Z. Zhang, P. Kurz et al., "The NOD2 defect in Blau syndrome does not result in excess interleukin-1 activity," Arthritis and Rheumatism, vol. 60, no. 2, pp. 611-618, 2009.

[103] D. O. Hacihamdioglu and S. Ozen, "Canakinumab induces remission in a patient with resistant familial Mediterranean fever," Rheumatology, vol. 51, no. 6, Article ID kes021, p. 1041, 2012.

[104] I. Mitroulis, P. Skendros, A. Oikonomou, A. G. Tzioufas, and K. Ritis, "The efficacy of canakinumab in the treatment of a patient with familial Mediterranean fever and longstanding destructive arthritis," Annals of the Rheumatic Diseases, vol. 70, no. 7, pp. 1347-1348, 2011.

[105] M. G. Brizi, M. Galeazzi, O. M. Lucherini, L. Cantarini, and R. Cimaz, "Successful treatment of tumor necrosis factor receptorassociated periodic syndrome with canakinumab," Annals of Internal Medicine, vol. 156, no. 12, pp. 907-908, 2012.

[106] M. Gattorno, L. Obici, and A. Meini, "Efficacy and safety of canakinumab in patients with TNF receptor-associated periodic syndrome," Arthritis \& Rheumatism, vol. 64, article 749, 2012.

[107] G. Lopalco, D. Rigante, A. Vitale, B. Frediani, F. Iannone, and L. Cantarini, "Tumor necrosis factor receptor-associated periodic syndrome managed with the couple canakinumabalendronate," Clinical Rheumatology, 2014.

[108] C. H. Sibley, A. Chioato, S. Felix et al., "A 24-month openlabel study of canakinumab in neonatal-onset multisystem inflammatory disease," Annals of the Rheumatic Diseases, 2014.

[109] R. Caorsi, L. Lepore, F. Zulian et al., "The schedule of administration of canakinumab in cryopyrin associated periodic syndrome is driven by the phenotype severity rather than the age," Arthritis Research and Therapy, vol. 15, article R33, 2013. 
[110] T. Imagawa, R. Nishikomori, H. Takada et al., "Safety and efficacy of canakinumab in Japanese patients with phenotypes of cryopyrin-associated periodic syndrome as established in the first open-label, phase-3 pivotal study (24-week results)," Clinical and Experimental Rheumatology, vol. 31, no. 2, pp. 302309, 2013.

[111] S. M. Mueller, P. Itin, and P. Haeusermann, "Muckle-wells syndrome effectively treated with canakinumab: is the recommended dosing schedule mandatory?" Dermatology, vol. 223, no. 2, pp. 113-118, 2011.

[112] H. J. Lachmann, I. Kone-Paut, J. B. Kuemmerle-Deschner et al., "Canakinumab in CAPS Study Group. Use of canakinumab in the cryopyrin-associated periodic syndrome," The New England Journal of Medicine, vol. 360, no. 23, pp. 2416-2425, 2009.

[113] I. Koné-Paut, H. J. Lachmann, J. B. Kuemmerle-Deschner et al., "Sustained remission of symptoms and improved health-related quality of life in patients with cryopyrin-associated periodic syndrome treated with canakinumab: results of a double-blind placebo-controlled randomized withdrawal study," Arthritis Research and Therapy, vol. 13, no. 6, article no. R202, 2011.

[114] J. B. Kuemmerle-Deschner, E. Ramos, N. Blank et al., "Canakinumab (ACZ885, a fully human IgG1 anti-IL-1 $\beta \mathrm{mAb}$ ) induces sustained remission in pediatric patients with cryopyrinassociated periodic syndrome (CAPS)," Arthritis Research and Therapy, vol. 13, article R34, 2011.

[115] J. B. Kuemmerle-Deschner, E. Hachulla, R. Cartwright et al., "Two-year results from an open-label, multicentre, phase III study evaluating the safety and efficacy of canakinumab in patients with cryopyrin-associated periodic syndrome across different severity phenotypes," Annals of the Rheumatic Diseases, vol. 70, no. 12, pp. 2095-2102, 2011.

[116] R. Scarpioni, D. Rigante, L. Cantarini et al., "Renal involvement in secondary amyloidosis of Muckle-Wells syndrome: marked improvement of renal function and reduction of proteinuria after therapy with human anti-interleukin-1 $\beta$ monoclonal antibody canakinumab," Clinical Rheumatology, 2014.

[117] A. Geusau, N. Mothes-Luksch, H. Nahavandi et al., "Identification of a homozygous PSTPIP1 mutation in a patient with a PAPA-like syndrome responding to canakinumab treatment," JAMA Dermatology, vol. 149, no. 2, pp. 209-215, 2013.

[118] G. Simonini, Z. Xu, R. Caputo et al., "Clinical and transcriptional response to the long-acting interleukin-1 blocker canakinumab in Blau syndrome-related uveitis," Arthritis and Rheumatism, vol. 65, no. 2, pp. 513-518, 2013.

[119] P. J. Hashkes, S. J. Spalding, E. H. Giannini et al., "Rilonacept for colchicine-resistant or -intolerant familial Mediterranean fever: a randomized trial," Annals of Internal Medicine, vol. 157, no. 8, pp. 533-541, 2012.

[120] P. J. Hashkes, S. J. Spalding, R. Hajj-Ali et al., "The effect of rilonacept versus placebo on health-related quality of life in patients with poorly controlled familial Mediterranean fever," BioMed Research International, vol. 2014, Article ID 854842, 8 pages, 2014.

[121] B. Huang, E. H. Giannini, D. J. Lovell, L. Ding, Y. Liu, and P. J. Hashkes, "Enhancing crossover trial design for rare diseases: limiting ineffective exposure and increasing study power by enabling patient choice to escape early," Contemporary Clinical Trials, vol. 38, no. 2, pp. 204-212, 2014.

[122] L. D. Church, S. Savic, and M. F. McDermott, "Long term management of patients with cryopyrin-associated periodic syndromes (CAPS): focus on rilonacept (IL-1 Trap)," Biologics: Targets and Therapy, vol. 2, no. 4, pp. 733-742, 2008.
[123] J. Gillespie, R. Mathews, and M. F. McDermott, "Rilonacept in the management of cryopyrin-associated periodic syndromes (CAPS)," Journal of Inflammation Research, vol. 3, no. 1, pp. 1-8, 2010.

[124] R. Goldbach-Mansky, S. D. Shroff, M. Wilson et al., "A pilot study to evaluate the safety and efficacy of the long-acting interleukin-1 inhibitor rilonacept (interleukin-1 trap) in patients with familial cold autoinflammatory syndrome," Arthritis \& Rheumatism, vol. 58, no. 8, pp. 2432-2442, 2008.

[125] H. M. Hoffman, M. L. Throne, N. J. Amar et al., "Efficacy and safety of rilonacept (interleukin-1 trap) in patients with cryopyrin-associated periodic syndromes: results from two sequential placebo-controlled studies," Arthritis and Rheumatism, vol. 58, no. 8, pp. 2443-2452, 2008.

[126] H. M. Hoffman, M. L. Throne, N. J. Amar et al., "Long-term efficacy and safety profile of rilonacept in the treatment of cryopryin-associated periodic syndromes: results of a 72-week open-label extension study," Clinical Therapeutics, vol. 34, no. 10, pp. 2091-2103, 2012.

[127] H. M. Hoffman, "Rilonacept for the treatment of cryopyrinassociated periodic syndromes (CAPS)," Expert Opinion on Biological Therapy, vol. 9, no. 4, pp. 519-531, 2009.

[128] S. Kapur, M. E. Bonk, and A. Caspi, "Rilonacept (arcalyst), an interleukin-I trap for the treatment of cryopyrin-associated periodic syndromes," Pharmacology \& Therapeutics, vol. 34, no. 3, pp. 138-141, 2009.

[129] K. T. Thomas, H. M. Feder Jr., A. R. Lawton, and K. M. Edwards, "Periodic fever syndrome in children," The Journal of Pediatrics, vol. 135, no. 1, pp. 15-21, 1999.

[130] S. Padeh, N. Brezniak, D. Zemer et al., "Periodic fever, aphthous stomatitis, pharyngitis, and adenopathy syndrome: clinical characteristics and outcome," Journal of Pediatrics, vol. 135, no. 1, pp. 98-101, 1999.

[131] D. C. Knockaert, L. J. Vanneste, and H. J. Bobbaers, "Recurrent or episodic fever of unknown origin: review of 45 cases and survey of the literature," Medicine, vol. 72, no. 3, pp. 184-196, 1993.

[132] G. S. Marshall, K. M. Edwards, J. Butler, and A. R. Lawton, "Syndrome of periodic fever, pharyngitis, and aphthous stomatitis," Journal of Pediatrics, vol. 110, no. 1, pp. 43-46, 1987.

[133] L. Cantarini, A. Vitale, B. Bartolomei, M. Galeazzi, and D. Rigante, "Diagnosis of PFAPA syndrome applied to a cohort of 17 adults with unexplained recurrent fevers," Clinical and Experimental Rheumatology, vol. 30, no. 2, pp. 269-271, 2012.

[134] J. Førsvoll, E. K. Kristoffersen, and K. Øymar, "Elevated levels of CXCL10 in the periodic fever, aphthous stomatitis, pharyngitis and cervical adenitis syndrome (PFAPA) during and between febrile episodes; an indication of a persistent activation of the innate immune system," Pediatric Rheumatology, vol. 11, article 38, 2013.

[135] K. L. Brown, P. Wekell, V. Osla et al., "Profile of blood cells and inflammatory mediators in periodic fever, aphthous stomatitis, pharyngitis and adenitis (PFAPA) syndrome," BMC Pediatrics, vol. 10, article 65, 2010.

[136] D. Rigante, "The protean visage of systemic autoinflammatory syndromes: a challenge for inter-professional collaboration," European Review for Medical and Pharmacological Sciences, vol. 14, no. 1, pp. 1-18, 2010.

[137] S. Stojanov, F. Hoffmann, A. Kéry et al., "Cytokine profile in PFAPA syndrome suggests continuous inflammation and reduced anti-inflammatory response," European Cytokine Network, vol. 17, no. 2, pp. 90-97, 2006. 
[138] L. Kolly, N. Busso, A. von Scheven-Gete et al., "Periodic fever, aphthous stomatitis, pharyngitis, cervical adenitis syndrome is linked to dysregulated monocyte IL- $1 \beta$ production," Journal of Allergy and Clinical Immunology, vol. 131, no. 6, pp. 1635-1643, 2013.

[139] S. Stojanov, S. Lapidus, P. Chitkara et al., "Periodic fever, aphthous stomatitis, pharyngitis, and adenitis (PFAPA) is a disorder of innate immunity and Th1 activation responsive to IL-1 blockade," Proceedings of the National Academy of Sciences of the United States of America, vol. 108, no. 17, pp. 7148-7153, 2011.

[140] L. Cantarini, A. Vitale, M. Galeazzi, and B. Frediani, "A case of resistant adult-onset periodic fever, aphtous stomatitis, pharyngitis and cervical adenitis (PFAPA) syndrome responsive to anakinra," Clinical and Experimental Rheumatology, vol. 30, no. 4, p. 593, 2012.

[141] C. Bansard, T. Lequerré, C. Derambure et al., "Gene profiling predicts rheumatoid arthritis responsiveness to IL-1Ra (anakinra)," Rheumatology, vol. 50, no. 2, pp. 283-292, 2011.

[142] N. J. Olsen and C. M. Stein, "New drugs for rheumatoid arthritis," The New England Journal of Medicine, vol. 350, no. 21, pp. 2167-2226, 2004.

[143] J. S. Smolen, D. Aletaha, M. Koeller, M. H. Weisman, and P. Emery, "New therapies for treatment of rheumatoid arthritis," The Lancet, vol. 370, no. 9602, pp. 1861-1874, 2007.

[144] J. F. Camargo, P. A. Correa, J. Castiblanco, and J. M. Anaya, "Interleukin-1beta polymorphisms in Colombian patients with autoimmune rheumatic diseases," Genes and Immunity, vol. 5, no. 8, pp. 609-614, 2004.

[145] S. Miyata, Y. Ohkubo, and S. Mutoh, "A review of the action of tacrolimus (FK506) on experimental models of rheumatoid arthritis," Inflammation Research, vol. 54, no. 1, pp. 1-9, 2005.

[146] R. M. Fleischmann, J. Schechtman, R. Bennett et al., "Anakinra, a recombinant human interleukin-1 receptor antagonist ( $r-$ metHuIL-1ra), in patients with rheumatoid arthritis: a large, international, multicenter, placebo-controlled trial," Arthritis \& Rheumatism, vol. 48, no. 4, pp. 927-934, 2003.

[147] B. Bresnihan, J. M. Alvaro-Gracia, M. Cobby et al., “Treatment of rheumatoid arthritis with recombinant human interleukin-1 receptor antagonist," Arthritis \& Rheumatism, vol. 41, no. 12, pp. 2196-2204, 1998.

[148] S. B. Abramson and A. Amin, "Blocking the effects of IL-1 in rheumatoid arthritis protects bone and cartilage," Rheumatology, vol. 41, no. 9, pp. 972-980, 2002.

[149] B. Bresnihan and M. Cobby, "Clinical and radiological effects of anakinra in patients with rheumatoid arthritis," Rheumatology, vol. 42, supplement 2, pp. ii22-ii28, 2003.

[150] J. A. Singh, R. Christensen, G. A. Wells et al., "Biologics for rheumatoid arthritis: an overview of Cochrane reviews," São Paulo Medical Journal, vol. 128, no. 5, pp. 309-310, 2010.

[151] J. Bao, T. Yue, W. Liu et al., "Secondary failure to treatment with recombinant human IL-1 receptor antagonist in Chinese patients with rheumatoid arthritis," Clinical Rheumatology, vol. 30, no. 5, pp. 697-701, 2011.

[152] B. Bresnihan, R. D. Newmark, S. Robbins, D. P. McCabe, and H. K. Genant, "Anakinra reduces the rate of joint destruction after 1 year of treatment in a randomized controlled cohort of patients with rheumatoid arthritis," Arthritis \& Rheumatism, vol. 43, supplement 9, article S289, 2000.

[153] G. Cunnane, A. Madigan, E. Murphy, O. FitzGerald, and B. Bresnihan, "The effects of treatment with interleukin-1 receptor antagonist on the inflamed synovial membrane in rheumatoid arthritis," Rheumatology, vol. 40, no. 1, pp. 62-69, 2001.

[154] E. B. Devine, R. Alfonso-Cristancho, and S. D. Sullivan, "Effectiveness of biologic therapies for rheumatoid arthritis: an indirect comparisons approach," Pharmacotherapy, vol. 31, no. 1, pp. 39-51, 2011.

[155] S.-Y. Wang, Y.-Y. Liu, H. Ye et al., "Circulating dickkopf-1 is correlated with bone erosion and inflammation in rheumatoid arthritis," The Journal of Rheumatology, vol. 38, no. 5, pp. 821$827,2011$.

[156] E. Turkstra, S.-K. Ng, and P. A. Scuffham, "A mixed treatment comparison of the short-term efficacy of biologic disease modifying anti-rheumatic drugs in established rheumatoid arthritis," Current Medical Research and Opinion, vol. 27, no. 10, pp. 18851897, 2011.

[157] R. Nixon, N. Bansback, and A. Brennan, "The efficacy of inhibiting tumour necrosis factor $\alpha$ and interleukin 1 in patients with rheumatoid arthritis: a meta-analysis and adjusted indirect comparisons," Rheumatology, vol. 46, no. 7, pp. 1140-1147, 2007.

[158] S. B. Cohen, V. Strand, D. Aguilar, and J. J. Ofman, "Patientversus physician-reported outcomes in rheumatoid arthritis patients treated with recombinant interleukin-1 receptor antagonist (anakinra) therapy," Rheumatology, vol. 43, no. 6, pp. 704711, 2004.

[159] S. B. Cohen, "The use of anakinra, an interleukin-1 receptor antagonist, in the treatment of rheumatoid arthritis," Rheumatic Disease Clinics of North America, vol. 30, no. 2, pp. 365-380, 2004.

[160] A. Kavanaugh, "Anakinra (interleukin-1 receptor antagonist) has positive effects on function and quality of life in patients with rheumatoid arthritis," Advances in Therapy, vol. 23, no. 2, pp. 208-217, 2006.

[161] S. B. Cohen, J. M. Woolley, and W. W. Chan, "Interleukin 1 receptor antagonist anakinra improves functional status in patients with rheumatoid arthritis," Journal of Rheumatology, vol. 30, no. 2, pp. 225-231, 2003.

[162] S. B. Cohen, L. W. Moreland, J. J. Cush et al., "A multicentre, double blind, randomised, placebo controlled trial of anakinra (Kineret), a recombinant interleukin 1 receptor antagonist, in patients with rheumatoid arthritis treated with background methotrexate," Annals of the Rheumatic Diseases, vol. 63, no. 9, pp. 1062-1068, 2004.

[163] B. Bresnihan, R. Newmark, S. Robbins, and H. K. Genant, "Effects of anakinra monotherapy on joint damage in patients with rheumatoid arthritis. Extension of a 24-Week randomized, placebo-controlled trial," The Journal of Rheumatology, vol. 31, no. 6, pp. 1103-1111, 2004.

[164] Y. Jiang, H. K. Genant, I. Watt et al., "A multicenter, doubleblind, dose-ranging, randomized, placebo-controlled studyof recombinant human interleukin-1 receptor antagonist in patients with rheumatoid arthritis: radiologic progression and correlation of Genant and Larsen scores," Arthritis \& Rheumatism, vol. 43, no. 5, pp. 1001-1009, 2000.

[165] H. K. Genant, B. Bresnihan, E. Ng, S. Robbins, R. D. Newmark, and D. McCabe, "Treatment with anakinra reduces the rate of joint destruction and shows accelerated benefit in the second 6 months of treatment for patients with rheumatoid arthritis," Annals of the Rheumatic Diseases, vol. 40, supplement 1, article $169,2001$.

[166] D. M. Miller, E. Ng, M. H. Schiff, S. B. Cohen, and B. Bresnihan, "Durability and rapidity of response for rheumatoid 
arthritis patients receiving therapy with anakinra," Annals of the Rheumatic Diseases, vol. 60, supplement 1, p. 171, 2001.

[167] G. Gartlehner, R. A. Hansen, B. L. Jonas, P. Thieda, and K. N. Lohr, "The comparative efficacy and safety of biologics for the treatment of rheumatoid arthritis: a systematic review and meta-analysis," Journal of Rheumatology, vol. 33, no. 12, pp. 2398-2408, 2006.

[168] M. Mertens and J. A. Singh, "Anakinra for rheumatoid arthritis: a systematic review," Journal of Rheumatology, vol. 36, no. 6, pp. 1118-1125, 2009.

[169] B. Blumenauer, M. Judd, A. Cranney et al., "Etanercept for the treatment of rheumatoid arthritis," Cochrane Database of Systematic Reviews, no. 4, Article ID CD004525, 2003.

[170] F. Navarro-Sarabia, R. Ariza-Ariza, B. Hernandez-Cruz, and I. Villanueva, "Adalimumab for treating rheumatoid arthritis," The Cochrane Database of Systematic Reviews, no. 3, Article ID CD005113, 2005.

[171] R. Alten, J. Gomez-Reino, P. Durez et al., "Efficacy and safety of the human anti-IL-1beta monoclonal antibody canakinumab in rheumatoid arthritis: results of a 12-week, phase II, dose-finding study," BMC Musculoskeletal Disorders, vol. 12, article 153, 2011.

[172] I. Demin, B. Hamrén, O. Luttringer, G. Pillai, and T. Jung, "Longitudinal model-based meta-analysis in rheumatoid arthritis: an application toward model-based drug development," Clinical Pharmacology and Therapeutics, vol. 92, no. 3, pp. 352-359, 2012.

[173] K. Esposito, F. Nappo, F. Giugliano et al., "Meal modulation of circulating interleukin 18 and adiponectin concentrations in healthy subjects and in patients with type 2 diabetes mellitus," The American Journal of Clinical Nutrition, vol. 78, no. 6, pp. 1135-1140, 2003.

[174] R. Stienstra, L. A. B. Joosten, T. Koenen et al., "The inflammasome-mediated caspase-1 activation controls adipocyte differentiation and insulin sensitivity," Cell Metabolism, vol. 12, no. 6, pp. 593-605, 2011.

[175] K. Maedler, P. Sergeev, F. Ris et al., "Glucose-induced $\beta$ cell production of IL-1 $\beta$ contributes to glucotoxicity in human pancreatic islets," The Journal of Clinical Investigation, vol. 110, no. 6, pp. 851-860, 2002.

[176] K. Maedler, G. A. Spinas, R. Lehmann et al., "Glucose induces $\beta$-cell apoptosis via up regulation of the Fas receptor in human islets," Diabetes, vol. 50, no. 8, pp. 1683-1690, 2001.

[177] K. Maedler, A. Fontana, F. Ris et al., "FLIP switches Fasmediated glucose signaling in human pancreatic $\beta$ cells from apoptosis to cell replication," Proceedings of the National Academy of Sciences of the United States of America, vol. 99, no. 12, pp. 8236-8241, 2002.

[178] S. L. Masters, A. Dunne, S. L. Subramanian et al., "Activation of the NLRP3 inflammasome by islet amyloid polypeptide provides a mechanism for enhanced IL-1 $\beta 2$ in type 2 diabetes," Nature Immunology, vol. 11, no. 10, pp. 897-904, 2010.

[179] M. Y. Donath, D. J. Gross, E. Cerasi, and N. Kaiser, "Hyperglycemia-induced $\beta$-cell apoptosis in pancreatic islets of Psammomys obesus during development of diabetes," Diabetes, vol. 48, no. 4, pp. 738-744, 1999.

[180] D. LeRoith, " $\beta$-cell dysfunction and insulin resistance in type 2 diabetes: role of metabolic and genetic abnormalities," The American Journal of Medicine, vol. 113, no. 6, supplement, pp. 3-11, 2002.

[181] M. Y. Donath and P. A. Halban, "Decreased $\beta$-cell mass in diabetes: significance, mechanisms and therapeutic implications," Diabetologia, vol. 47, no. 3, pp. 581-589, 2004.
[182] C. M. Larsen, M. Faulenbach, A. Vaag et al., "Interleukin1-receptor antagonist in type 2 diabetes mellitus," The New England Journal of Medicine, vol. 356, no. 15, pp. 1517-1526, 2007.

[183] C. M. Larsen, M. Faulenbach, A. Vaag, J. A. Ehses, M. Y. Donath, and T. Mandrup-Poulsen, "Sustained effects of interleukin-1 receptor antagonist treatment in type 2 diabetes," Diabetes Care, vol. 32, no. 9, pp. 1663-1668, 2009.

[184] J. Hensen, C. P. Howard, V. Walter, and T. Thuren, "Impact of interleukin-1 $\beta$ antibody (canakinumab) on glycaemic indicators in patients with type 2 diabetes mellitus: results of secondary endpoints from a randomized, placebo-controlled trial," Diabetes and Metabolism, vol. 39, no. 6, pp. 524-531, 2013.

[185] P. M. Ridker, C. P. Howard, V. Walter et al., "Effects of interleukin- $1 \beta$ inhibition with canakinumab on hemoglobin Alc, lipids, C-reactive protein, interleukin-6, and fibrinogen a phase IIb randomized, placebo-controlled trial," Circulation, vol. 126, no. 23, pp. 2739-2748, 2012.

[186] A. Noe, C. Howard, T. Thuren, A. Taylor, and A. Skerjanec, "Pharmacokinetic and pharmacodynamic characteristics of single-dose canakinumab in patients with type 2 diabetes mellitus," Clinical Therapeutics, vol. 36, no. 11, pp. 1625-1637, 2014.

[187] C. Cavelti-Weder, R. Furrer, C. Keller et al., "Inhibition of IL-1 $\beta$ improves fatigue in type 2 diabetes," Diabetes Care, vol. 34, no. 10, article e158, 2011.

[188] C. Cavelti-Weder, A. Babians-Brunner, C. Keller et al., "Effects of gevokizumab on glycemia and inflammatory markers in type 2 diabetes," Diabetes Care, vol. 35, no. 8, pp. 1654-1662, 2012.

[189] A. M. Owyang, K. Maedler, L. Gross et al., "XOMA 052, an anti-IL-1 $\beta$ monoclonal antibody, improves glucose control and $\beta$-cell function in the diet-induced obesity mouse model," Endocrinology, vol. 151, no. 6, pp. 2515-2527, 2010.

[190] M. Handa, S. Vanegas, B. A. Maddux et al., "XOMA 052, an antiIL- $1 \beta$ monoclonal antibody, prevents IL- $1 \beta$-mediated insulin resistance in 3T3-L1 adipocytes," Obesity, vol. 21, no. 2, pp. 306309, 2013.

[191] C. Selmi, "Diagnosis and classification of autoimmune uveitis," Autoimmunity Reviews, vol. 13, no. 4-5, pp. 591-594, 2014.

[192] D. Lasigliè, E. Traggiai, S. Federici et al., "Role of IL-1 beta in the development of human $\mathrm{T}_{H} 17$ cells: lesson from NLPR3 mutated patients," PLoS ONE, vol. 6, no. 5, Article ID e20014, 2011.

[193] H. Kitamei, K. Iwabuchi, K. Namba et al., "Amelioration of experimental autoimmune uveoretinitis (EAU) with an inhibitor of nuclear factor- $\kappa \mathrm{B}(\mathrm{NF}-\kappa \mathrm{B})$, pyrrolidine dithiocarbamate," Journal of Leukocyte Biology, vol. 79, no. 6, pp. 11931201, 2006.

[194] A. Lennikov, N. Kitaichi, K. Noda et al., "Amelioration of endotoxin-induced uveitis treated with an $\mathrm{I} \kappa \mathrm{B}$ kinase $\beta$ inhibitor in rats," Molecular Vision, vol. 18, pp. 2586-2597, 2012.

[195] A. F. de Vos, V. N. A. Klaren, and A. Kijlstra, "Expression of multiple cytokines and IL-1RA in the uvea and retina during endotoxin-induced uveitis in the rat," Investigative Ophthalmology \& Visual Science, vol. 35, no. 11, pp. 3873-3883, 1994.

[196] G. Simonini, L. Cantarini, C. Bresci, M. Lorusso, M. Galeazzi, and R. Cimaz, "Current therapeutic approaches to autoimmune chronic uveitis in children," Autoimmunity Reviews, vol. 9, no. 10, pp. 674-683, 2010.

[197] W.-K. Lim, C. Fujimoto, R. Ursea et al., "Suppression of immune-mediated ocular inflammation in mice by interleukin 1 receptor antagonist administration," Archives of Ophthalmology, vol. 123, no. 7, pp. 957-963, 2005. 
[198] J. I. Aróstegui, C. Arnal, R. Merino et al., "NOD2 geneassociated pediatric granulomatous arthritis: clinical diversity, novel and recurrent mutations, and evidence of clinical improvement with interleukin-1 blockade in a Spanish cohort," Arthritis and Rheumatism, vol. 56, no. 11, pp. 3805-3813, 2007.

[199] A. Gül, I. Tugal-Tutkun, C. A. Dinarello et al., "Interleukin-1 $\beta$ regulating antibody XOMA 052 (gevokizumab) in the treatment of acute exacerbations of resistant uveitis of Behçet's disease: an open-label pilot study," Annals of the Rheumatic Diseases, vol. 71, no. 4, pp. 563-566, 2012.

[200] R. Shabetai, "Editorial: Often neglected yet important: the pericardium and its diseases," Herz, vol. 25, no. 8, pp. 717-719, 2000.

[201] W. C. Little and G. L. Freeman, "Pericardial disease," Circulation, vol. 113, no. 12, pp. 1622-1632, 2006.

[202] R. W. Troughton, C. R. Asher, and A. L. Klein, "Pericarditis," The Lancet, vol. 363, no. 9410, pp. 717-727, 2004.

[203] L. Cantarini, M. Imazio, M. G. Brizi et al., "Role of autoimmunity and autoinflammation in the pathogenesis of idiopathic recurrent pericarditis," Clinical Reviews in Allergy and Immunology, vol. 44, no. 1, pp. 6-13, 2013.

[204] M. Imazio, “Treatment of recurrent pericarditis," Expert Review of Cardiovascular Therapy, vol. 10, no. 9, pp. 1165-1172, 2012.

[205] S. Maestroni, P. R. Di Corato, D. Cumetti et al., "Recurrent pericarditis: autoimmune or autoinflammatory?" Autoimmunity Reviews, vol. 12, no. 1, pp. 60-65, 2012.

[206] C. A. Dinarello and J. W. M. van der Meer, "Treating inflammation by blocking interleukin-1 in humans," Seminars in Immunology, vol. 25, no. 6, pp. 469-484, 2013.

[207] P. Vasileiou, C. Tsioufis, G. Lazaros et al., "Interleukin-8 as a predictor of acute idiopathic pericarditis recurrences. A pilot study," International Journal of Cardiology, vol. 172, no. 3, pp. e463-e464, 2014.

[208] L. Cantarini, M. Imazio, A. Brucato, O. M. Lucherini, and M. Galeazzi, "Innate versus acquired immune response in the pathogenesis of recurrent idiopathic pericarditis," Autoimmunity Reviews, vol. 9, no. 6, pp. 436-440, 2010.

[209] M. Finetti, A. Insalaco, L. Cantarini et al., "Long-term efficacy of interleukin-1 receptor antagonist (anakinra) in corticosteroiddependent and colchicine-resistant recurrent pericarditis," The Journal of Pediatrics, vol. 164, no. 6, pp. 1425.el-1431.el, 2014.

[210] P. Picco, G. Brisca, F. Traverso, A. Loy, M. Gattorno, and A. Martini, "Successful treatment of idiopathic recurrent pericarditis in children with interleukin- $1 \beta$ receptor antagonist (anakinra): an unrecognized autoinflammatory disease?" Arthritis \& Rheumatism, vol. 60, no. 1, pp. 264-268, 2009.

[211] D. Vassilopoulos, G. Lazaros, C. Tsioufis, P. Vasileiou, C. Stefanadis, and D. Pectasides, "Successful treatment of adult patients with idiopathic recurrent pericarditis with an interleukin-1 receptor antagonist (anakinra)," International Journal of Cardiology, vol. 160, no. 1, pp. 66-68, 2012.

[212] D. Rigante, L. Cantarini, M. Imazio et al., "Autoinflammatory diseases and cardiovascular manifestations," Annals of Medicine, vol. 43, no. 5, pp. 341-346, 2011.

[213] K. M. Hull, E. Drewe, I. Aksentijevich et al., “The TNF receptorassociated periodic syndrome (TRAPS): emerging concepts of an autoinflammatory disorder," Medicine, vol. 81, no. 5, pp. 349368, 2002.

[214] A. Simon, H. Park, R. Maddipati et al., "Concerted action of wild-type and mutant TNF receptors enhances inflammation in
TNF receptor 1-associated periodic fever syndrome," Proceedings of the National Academy of Sciences of the United States of America, vol. 107, no. 21, pp. 9801-9806, 2010.

[215] L. Cantarini, O. M. Lucherini, C. T. Baldari, F. Laghi Pasini, and M. Galeazzi, "Familial clustering of recurrent pericarditis may disclose tumour necrosis factor receptor-associated periodic syndrome," Clinical and Experimental Rheumatology, vol. 28, no. 3, pp. 405-407, 2010.

[216] L. Cantarini, O. M. Lucherini, A. Vitale et al., "Expanding spectrum of TNFRSF1A gene mutations among patients with idiopathic recurrent acute pericarditis," Internal Medicine Journal, vol. 43, no. 6, pp. 725-727, 2013.

[217] L. Cantarini, D. Rigante, G. Merlini et al., "The expanding spectrum of low-penetrance TNFRSF1A gene variants in adults presenting with recurrent inflammatory attacks: clinical manifestations and long-term follow-up," Seminars in Arthritis and Rheumatism, vol. 43, no. 6, pp. 818-823, 2014.

[218] S. Maggiolini, G. Tiberti, L. Cantarini et al., "Large pericardial effusion in a family with recurrent pericarditis: a report of probable x-linked transmission," Experimental and Clinical Cardiology, vol. 16, no. 2, pp. 54-56, 2011.

[219] L. Cantarini, O. M. Lucherini, A. Brucato et al., "Clues to detect tumor necrosis factor receptor-associated periodic syndrome (TRAPS) among patients with idiopathic recurrent acute pericarditis: results of a multicentre study," Clinical Research in Cardiology, vol. 101, no. 7, pp. 525-531, 2012.

[220] L. Cantarini, O. M. Lucherini, R. Cimaz et al., "Idiopathic recurrent pericarditis refractory to colchicine treatment can reveal tumor necrosis factor receptor-associated periodic syndrome," International Journal of Immunopathology and Pharmacology, vol. 22, no. 4, pp. 1051-1058, 2009.

[221] L. Cantarini, G. Lopalco, C. Selmi et al., "Autoimmunity and autoinflammation as the yin and yang of idiopathic recurrent acute pericarditis," Autoimmunity Reviews, vol. 14, no. 2, pp. 9097, 2014.

[222] M. Camacho-Lovillo and A. Méndez-Santos, "Successful treatment of idiopathic recurrent pericarditis with interleukin-1 receptor antagonist (Anakinra)," Pediatric Cardiology, vol. 34, no. 5, pp. 1293-1294, 2013.

[223] A. Scardapane, A. Brucato, F. Chiarelli, and L. Breda, "Efficacy of an interleukin- $1 \beta$ receptor antagonist (anakinra) in idiopathic recurrent pericarditis," Pediatric Cardiology, vol. 34, no. 8, pp. 1989-1991, 2013.

[224] G. Lazaros, P. Vasileiou, C. Koutsianas et al., "Anakinra for the management of resistant idiopathic recurrent pericarditis. Initial experience in 10 adult cases," Annals of the Rheumatic Diseases, vol. 73, no. 12, pp. 2215-2217, 2014.

[225] L. Cantarini, G. Lopalco, A. Vitale et al., "Paradoxical mucocutaneous flare in a case of Behçet's disease treated with tocilizumab," Clinical Rheumatology, 2014.

[226] K. Hamzaoui, M. Hamza, and K. Ayed, "Production of TNF- $\alpha$ and IL-1 in active Behcet's disease," The Journal of Rheumatology, vol. 17, no. 10, pp. 1428-1429, 1990.

[227] S. Pay, H. Erdem, A. Pekel et al., "Synovial proinflammatory cytokines and their correlation with matrix metalloproteinase-3 expression in Behçet's disease. Does interleukin- $1 \beta$ play a major role in Behçet's synovitis?" Rheumatology International, vol. 26, no. 7, pp. 608-613, 2006.

[228] L. Cantarini, A. Vitale, M. Borri, M. Galeazzi, and R. Franceschini, "Successful use of canakinumab in a patient with resistant Behçet's disease," Clinical and Experimental Rheumatology, vol. 30, no. 3, supplement 72, article S115, 2012. 
[229] J. Karasneh, A. H. Hajeer, J. Barrett, W. E. R. Ollier, M. Thornhill, and A. Gul, "Association of specific interleukin 1 gene cluster polymorphisms with increased susceptibility for Behçet's disease," Rheumatology, vol. 42, no. 7, pp. 860-864, 2003.

[230] A. Akman, N. C. Ekinci, H. Kacaroglu, U. Yavuzer, E. Alpsoy, and O. Yegin, "Relationship between periodontal findings and specific polymorphisms of interleukin- $1 \alpha$ and $-1 \beta$ in Turkish patients with Behçet's disease," Archives of Dermatological Research, vol. 300, no. 1, pp. 19-26, 2008.

[231] M. Castrichini, P. E. Lazzerini, A. Gamberucci et al., "The purinergic $\mathrm{P} 2 \times 7$ receptor is expressed on monocytes in Behçet's disease and is modulated by TNF- $\alpha$, European Journal of Immunology, vol. 44, no. 1, pp. 227-238, 2014.

[232] L. Cantarini, A. Vitale, P. Scalini et al., "Anakinra treatment in drug-resistant Behçet's disease: a case series," Clinical Rheumatology, 2013.

[233] F. Caso, D. Rigante, A. Vitale, O. M. Lucherini, and L. Cantarini, "Efficacy of anakinra in refractory Behçet's disease sacroiliitis," Clinical and Experimental Rheumatology, vol. 32, no. 4, supplement 84, p. S171, 2014.

[234] Y. Bilginer, N. A. Ayaz, and S. Ozen, "Anti-IL-1 treatment for secondary amyloidosis in an adolescent with FMF and Behçet's disease," Clinical Rheumatology, vol. 29, no. 2, pp. 209-210, 2010.

[235] C. Botsios, P. Sfriso, A. Furlan, L. Punzi, and C. A. Dinarello, "Resistant Behçet disease responsive to anakinra," Annals of Internal Medicine, vol. 149, no. 4, pp. 284-286, 2008.

[236] G. Emmi, E. Silvestri, A. M. Cameli et al., "Anakinra for resistant Behçet uveitis: why not?" Clinical and Experimental Rheumatology, vol. 31, no. 3, supplement 77, pp. S152-S153, 2013.

[237] A. Vitale, D. Rigante, F. Caso et al., "Inhibition of interleukin1 by canakinumab as a successful mono-drug strategy for the treatment of refractory Behçet's disease: a case series," Dermatology, vol. 228, no. 3, pp. 211-214, 2014.

[238] S. Ugurlu, D. Ucar, E. Seyahi, G. Hatemi, and S. Yurdakul, "Canakinumab in a patient with juvenile Behçet's syndrome with refractory eye disease," Annals of the Rheumatic Diseases, vol. 71, no. 9, pp. 1589-1591, 2012.

[239] L. Cantarini, G. Lopalco, F. Caso et al., "Effectiveness and tuberculosis-related safety profile of interleukin-1 blocking agents in the management of Behçet's disease," Autoimmunity Reviews, vol. 14, no. 1, pp. 1-9, 2015.

[240] F. Caso, L. Costa, D. Rigante et al., "Biological treatments in Behçet's disease: beyond anti-TNF therapy," Mediators of Inflammation, vol. 2014, Article ID 107421, 14 pages, 2014.

[241] L. Cantarini, I. Tinazzi, P. Caramaschi, F. Bellisai, A. Brogna, and M. Galeazzi, "Safety and efficacy of etanercept in children with juvenile-onset Behcet's disease," International Journal of Immunopathology and Pharmacology, vol. 22, no. 2, pp. 551-555, 2009.

[242] N. Busso and A. So, "Mechanisms of inflammation in gout," Arthritis Research and Therapy, vol. 12, no. 2, article 206, 2010.

[243] F. Martinon, V. Pétrilli, A. Mayor, A. Tardivel, and J. Tschopp, "Gout-associated uric acid crystals activate the NALP3 inflammasome," Nature, vol. 440, no. 7081, pp. 237-241, 2006.

[244] C.-J. Chen, Y. Shi, A. Hearn et al., "MyD88-dependent IL-1 receptor signaling is essential for gouty inflammation stimulated by monosodium urate crystals," The Journal of Clinical Investigation, vol. 116, no. 8, pp. 2262-2271, 2006.

[245] P. Pelegrin and A. Surprenant, "Pannexin-1 couples to maitotoxin- and nigericin-induced interleukin-1beta release through a dye uptake-independent pathway," The Journal of Biological Chemistry, vol. 282, no. 4, pp. 2386-2394, 2007.

[246] A. M. Owyang, H. Issafras, J. Corbin et al., "XOMA 052, a potent, high-affinity monoclonal antibody for the treatment of IL-1 $\beta$-mediated diseases," $m A b s$, vol. 3, no. 1, pp. 49-60, 2011.

[247] S. B. Gratton, K. J. Scalapino, and K. H. Fye, "Case of anakinra as a steroid-sparing agent for gout inflammation," Arthritis Care and Research, vol. 61, no. 9, pp. 1268-1270, 2009.

[248] D. McGonagle, A. L. Tan, S. Shankaranarayana, J. Madden, P. Emery, and M. F. McDermott, "Management of treatment resistant inflammation of acute on chronic tophaceous gout with anakinra," Annals of the Rheumatic Diseases, vol. 66, no. 12, pp. 1683-1684, 2007.

[249] D. McGonagle, A. L. Tan, J. Madden, P. Emery, and M. F. McDermott, "Successful treatment of resistant pseudogout with anakinra," Arthritis and Rheumatism, vol. 58, no. 2, pp. 631-633, 2008.

[250] D. Singh and K. K. Huston, "IL-1 inhibition with anakinra in a patient with refractory gout," Journal of Clinical Rheumatology, vol. 15, no. 7, p. 366, 2009.

[251] A. So, T. de Smedt, S. Revaz, and J. Tschopp, "A pilot study of IL1 inhibition by anakinra in acute gout," Arthritis Research and Therapy, vol. 9, article R28, 2007.

[252] N. Announ, G. Palmer, P. A. Guerne, and C. Gabay, "Anakinra is a possible alternative in the treatment and prevention of acute attacks of pseudogout in end-stage renal failure," Joint Bone Spine, vol. 76, no. 4, pp. 424-426, 2009.

[253] A. Vitale, L. Cantarini, D. Rigante, M. Bardelli, and M. Galeazzi, "Anakinra treatment in patients with gout and type 2 diabetes," Clinical Rheumatology, 2014.

[254] A. So, M. de Meulemeester, A. Pikhlak et al., "Canakinumab for the treatment of acute flares in difficult-to-treat gouty arthritis: results of a multicenter, phase II, dose-ranging study," Arthritis \& Rheumatism, vol. 62, no. 10, pp. 3064-3076, 2010.

[255] N. Schlesinger, M. de Meulemeester, A. Pikhlak et al., "Canakinumab relieves symptoms of acute flares and improves health-related quality of life in patients with difficult-to-treat Gouty Arthritis by suppressing inflammation: results of a randomized, dose-ranging study," Arthritis Research and Therapy, vol. 13, no. 2, article R53, 2011.

[256] N. Schlesinger, E. Mysler, H.-Y. Lin et al., "Canakinumab reduces the risk of acute gouty arthritis flares during initiation of allopurinol treatment: results of a double-blind, randomised study," Annals of the Rheumatic Diseases, vol. 70, no. 7, pp. 12641271, 2011.

[257] N. Schlesinger, R. E. Alten, T. Bardin et al., "Canakinumab for acute gouty arthritis in patients with limited treatment options: results from two randomised, multicentre, active-controlled, double-blind trials and their initial extensions," Annals of the Rheumatic Diseases, vol. 71, no. 11, pp. 1839-1848, 2012.

[258] E. Mitha, H. R. Schumacher, L. Fouche et al., "Rilonacept for gout flare prevention during initiation of uric acid-lowering therapy: results from the PRESURGE-2 international, phase 3, randomized, placebo-controlled trial," Rheumatology, vol. 52, no. 7, pp. 1285-1292, 2013.

[259] H. R. Schumacher Jr., R. R. Evans, K. G. Saag et al., "Rilonacept (interleukin-1 trap) for prevention of gout flares during initiation of uric acid-lowering therapy: results from a phase III randomized, double-blind, placebo-controlled, confirmatory efficacy study," Arthritis Care and Research, vol. 64, no. 10, pp. 1462-1470, 2012. 
[260] R. A. Terkeltaub, H. R. Schumacher, J. D. Carter et al., "Rilonacept in the treatment of acute gouty arthritis: a randomized, controlled clinical trial using indomethacin as the active comparator," Arthritis Research \& Therapy, vol. 15, no. 1, article R25, 2013.

[261] R. Terkeltaub, J. S. Sundy, H. R. Schumacher et al., "The interleukin 1 inhibitor rilonacept in treatment of chronic gouty arthritis: results of a placebo-controlled, monosequence crossover, non-randomised, single-blind pilot study," Annals of the Rheumatic Diseases, vol. 68, no. 10, pp. 1613-1617, 2009.

[262] A. Solomon, D. Dursun, Z. Liu, Y. Xie, A. Macri, and S. C. Pflugfelder, "Pro- and anti-inflammatory forms of interleukin1 in the tear fluid and conjunctiva of patients with dry-eye disease," Investigative Ophthalmology and Visual Science, vol. 42, no. 10, pp. 2283-2292, 2001.

[263] M. Azuma, K. Motegi, K. Aota, Y. Hayashi, and M. Sato, "Role of cytokines in the destruction of acinar structure in Sjögren's syndrome salivary glands," Laboratory Investigation, vol. 77, no. 3, pp. 269-280, 1997.

[264] P. Willeke, H. Schotte, B. Schlüter et al., "Interleukin 1beta and tumour necrosis factor $\alpha$ secreting cells are increased in the peripheral blood of patients with primary Sjögren's syndrome," Annals of the Rheumatic Diseases, vol. 62, no. 4, pp. 359-362, 2003.

[265] R. I. Fox, H.-I. Kang, D. Ando, J. Abrams, and E. Pisa, “Cytokine mRNA expression in salivary gland biopsies of Sjögren's syndrome," The Journal of Immunology, vol. 152, no. 11, pp. 55325539, 1994.

[266] J.-J. Dubost, S. Perrier, M. Afane et al., "IL-1 receptor antagonist in saliva; characterization in normal saliva and reduced concentration in Sjogren's syndrome (SS)," Clinical and Experimental Immunology, vol. 106, no. 2, pp. 237-242, 1996.

[267] Y.-T. Chen, S. Lazarev, A. F. Bahrami et al., "Interleukin-1 receptor mediates the interplay between $\mathrm{CD}^{+} \mathrm{T}$ cells and ocular resident cells to promote keratinizing squamous metaplasia in Sjögren's syndrome," Laboratory Investigation, vol. 92, no. 4, pp. 556-570, 2012.

[268] Y. Muraki, A. Tsutsumi, R. Takahashi et al., "Polymorphisms of IL-1 $\beta$ gene in Japanese patients with Sjogren's syndrome and systemic lupus erythematosus," The Journal of Rheumatology, vol. 31, no. 4, pp. 720-725, 2004.

[269] S. Hurst and S. M. Collins, "Interleukin- $1 \beta$ modulation of norepinephrine release from rat myenteric nerves," American Journal of Physiology-Gastrointestinal and Liver Physiology, vol. 264, no. 1, pp. G30-G35, 1993.

[270] C. A. Murray, B. McGahon, S. McBennett, and M. A. Lynch, "Interleukin-1 $\beta$ inhibits glutamate release in hippocampus of young, but not aged, rats," Neurobiology of Aging, vol. 18, no. 3, pp. 343-348, 1997.

[271] D. Zoukhri, R. R. Hodges, D. Byon, and C. L. Kublin, "Role, of proinflammatory cytokines in the impaired lacrimation associated with autoimmune xerophthalmia," Investigative Ophthalmology and Visual Science, vol. 43, no. 5, pp. 1429-1436, 2002.

[272] M. Bulosan, K. M. Pauley, K. Yo et al., "Inflammatory caspases are critical for enhanced cell death in the target tissue of Sjögren's syndrome before disease onset," Immunology and Cell Biology, vol. 87, no. 1, pp. 81-90, 2009.

[273] S. Eltom, C. S. Stevenson, J. Rastrick et al., "P2x7 receptor and caspase 1 activation are central to airway inflammation observed after exposure to tobacco smoke," PLOS ONE, vol. 6, no. 9, Article ID e24097, 2011.
[274] H. J. Anders and D. A. Muruve, "The inflammasomes in kidney disease," Journal of the American Society of Nephrology, vol. 22, no. 6, pp. 1007-1018, 2011.

[275] B. Vandanmagsar, Y. H. Youm, A. Ravussin et al., "The NLRP3 inflammasome instigates obesity-induced inflammation and insulin resistance," Nature Medicine, vol. 17, no. 2, pp. 179-189, 2011.

[276] A. Yamada, R. Arakaki, Y. Kudo, and N. Ishimaru, "Targeting IL-1 in Sjögren's syndrome," Expert Opinion on Therapeutic Targets, vol. 17, no. 4, pp. 393-401, 2013.

[277] K. B. Norheim, E. Harboe, L. G. Gøransson, and R. Omdal, "Interleukin-1 inhibition and fatigue in primary sjögren's syndrome-a double blind, randomised clinical trial," PLoS ONE, vol. 7, no. 1, Article ID e30123, 2012.

[278] F. Amparo, M. H. Dastjerdi, A. Okanobo et al., “Topical interleukin 1 receptor antagonist for treatment of dry eye disease: a randomized clinical trial," JAMA Ophthalmology, vol. 131, no. 6, pp. 715-723, 2013.

[279] T. E. King Jr., "Clinical advances in the diagnosis and therapy of the interstitial lung diseases," American Journal of Respiratory and Critical Care Medicine, vol. 172, no. 3, pp. 268-279, 2005.

[280] G. A. Koretzky, J. A. Elias, S. L. Kay, M. D. Rossman, P. C. Nowell, and R. P. Daniele, "Spontaneous production of interleukin1 by human alveolar macrophages," Clinical Immunology and Immunopathology, vol. 29, no. 3, pp. 443-450, 1983.

[281] S. Nagai, M. Takeuchi, K. Watanabe, H. Aung, and T. Izumi, "Smoking and interleukin-1 activity released from human alveolar macrophages in healthy subjects," Chest, vol. 94, no. 4, pp. 694-700, 1988.

[282] M. Takeuchi, S. Nagai, H. Nakada et al., "Characterization of IL-1 inhibitory factor released from human alveolar macrophages as IL-1 receptor antagonist," Clinical and Experimental Immunology, vol. 88, no. 1, pp. 181-187, 1992.

[283] C. A. Dinarello, "Interleukin-1," Cytokine and Growth Factor Reviews, vol. 8, no. 4, pp. 253-265, 1997.

[284] L. H. Pan, H. Ohtani, K. Yamauchi, and H. Nagura, "Coexpression of TNF $\alpha$ and IL- $1 \beta$ in human acute pulmonary fibrotic diseases: an immunohistochemical analysis," Pathology International, vol. 46, no. 2, pp. 91-99, 1996.

[285] C. J. Johnston, B. Piedboeuf, P. Rubin, J. P. Williams, R. Baggs, and J. N. Finkelstein, "Early and persistent alterations in the expression of interleukin- $1 \alpha$, interleukin- $1 \beta$ and tumor necrosis factor $\alpha$ mRNA levels in fibrosis-resistant and sensitive mice after thoracic irradiation," Radiation Research, vol. 145, no. 6, pp. 762-767, 1996.

[286] M. Kolb, P. J. Margetts, D. C. Anthony, F. Pitossi, and J. Gauldie, "Transient expression of IL-1 $\beta$ induces acute lung injury and chronic repair leading to pulmonary fibrosis," The Journal of Clinical Investigation, vol. 107, no. 12, pp. 1529-1536, 2001.

[287] P. J. Sime, Z. Xing, F. L. Graham, K. G. Csaky, and J. Gauldie, "Adenovector-mediated gene transfer of active transforming growth factor- $\beta 1$ induces prolonged severe fibrosis in rat lung," The Journal of Clinical Investigation, vol. 100, no. 4, pp. 768-776, 1997.

[288] P. F. Piguet, C. Vesin, G. E. Grau, and R. C. Thompson, "Interleukin 1 receptor antagonist (IL-1ra) prevents or cures pulmonary fibrosis elicited in mice by bleomycin or silica," Cytokine, vol. 5, no. 1, pp. 57-61, 1993.

[289] R. W. Wilmott, J. A. Kitzmiller, M. A. Fiedler, and J. M. Stark, "Generation of a transgenic mouse with lung-specific overexpression of the human interleukin-1 receptor antagonist 
protein," American Journal of Respiratory Cell and Molecular Biology, vol. 18, no. 3, pp. 429-434, 1998.

[290] N. P. Barlo, C. H. M. van Moorsel, N. M. Korthagen et al., "Genetic variability in the ILIRN gene and the balance between interleukin (IL)-1 receptor agonist and IL-1 $\beta$ in idiopathic pulmonary fibrosis," Clinical and Experimental Immunology, vol. 166, no. 3, pp. 346-351, 2011.

[291] S. Reddy, S. Jia, R. Geoffrey et al., "An autoinflammatory disease due to homozygous deletion of the ILIRN locus," The New England Journal of Medicine, vol. 360, no. 23, pp. 2438-2444, 2009.

[292] S. L. Cassel, S. C. Eisenbarth, S. S. Iyer et al., "The Nalp3 inflammasome is essential for the development of silicosis," Proceedings of the National Academy of Sciences of the United States of America, vol. 105, no. 26, pp. 9035-9040, 2008.

[293] C. M. Artlett, S. Sassi-Gaha, J. L. Rieger, A. C. Boesteanu, C. A. Feghali-Bostwick, and P. D. Katsikis, "The inflammasome activating caspase 1 mediates fibrosis and myofibroblast differentiation in systemic sclerosis," Arthritis \& Rheumatism, vol. 63, no. 11, pp. 3563-3574, 2011.

[294] A. Furlan, C. Botsios, A. Ruffatti, S. Todesco, and L. Punzi, "Antisynthetase syndrome with refractory polyarthritis and fever successfully treated with the IL-1 receptor antagonist, anakinra: a case report," Joint Bone Spine, vol. 75, no. 3, pp. 366367, 2008.

[295] S. M. Keidel, R. K. Hoyles, and N. M. R. Wilkinson, "Efficacy of tocilizumab for interstitial lung disease in an undifferentiated autoinflammatory disorder partially responsive to anakinra," Rheumatology, vol. 53, no. 3, Article ID ket211, pp. 573-574, 2014.

[296] A. Kontzias and P. Efthimiou, "Adult-onset still's disease: pathogenesis, clinical manifestations and therapeutic advances," Drugs, vol. 68, no. 3, pp. 319-337, 2008.

[297] J.-H. Choi, C.-H. Suh, Y.-M. Lee et al., "Serum cytokine profiles in patients with adult onset Still's disease," Journal of Rheumatology, vol. 30, no. 11, pp. 2422-2427, 2003.

[298] D.-Y. Chen, J.-L. Lan, F.-J. Lin, and T.-Y. Hsieh, "Proinflammatory cytokine profiles in sera and pathological tissues of patients with active untreated adult onset still's disease," The Journal of Rheumatology, vol. 31, no. 11, pp. 2189-2198, 2004.

[299] A. Stabile, B. Bertoni, V. Ansuini, I. la Torraca, A. Sallì, and D. Rigante, "The clinical spectrum and treatment options of macrophage activation syndrome in the pediatric age," European Review for Medical and Pharmacological Sciences, vol. 10, no. 2, pp. 53-59, 2006.

[300] V. Pascual, F. Allantaz, E. Arce, M. Punaro, and J. Banchereau, "Role of interleukin-1 (IL-1) in the pathogenesis of systemic onset juvenile idiopathic arthritis and clinical response to IL1 blockade," The Journal of Experimental Medicine, vol. 201, no. 9, pp. 1479-1486, 2005.

[301] L. Naumann, E. Feist, A. Natusch et al., "IL1-receptor antagonist anakinra provides long-lasting efficacy in the treatment of refractory adult-onset Still's disease," Annals of the Rheumatic Diseases, vol. 69, no. 2, pp. 466-467, 2010.

[302] T. Lequerré, P. Quartier, D. Rosellini et al., "Interleukin-1 receptor antagonist (anakinra) treatment in patients with systemiconset juvenile idiopathic arthritis or adult onset Still disease: preliminary experience in France," Annals of the Rheumatic Diseases, vol. 67, no. 3, pp. 302-308, 2008.

[303] I. Kötter, A. Wacker, S. Koch et al., "Anakinra in patients with treatment-resistant adult-onset Still's disease: four case reports with serial cytokine measurements and a review of the literature," Seminars in Arthritis and Rheumatism, vol. 37, no. 3, pp. 189-197, 2007.

[304] G. D. Kalliolias, P. E. Georgiou, I. A. Antonopoulos, A. P. Andonopoulos, and S.-N. C. Liossis, "Anakinra treatment in patients with adult-onset Still's disease is fast, effective, safe and steroid sparing: experience from an uncontrolled trial," Annals of the Rheumatic Diseases, vol. 66, no. 6, pp. 842-843, 2007.

[305] A. A. Fitzgerald, S. A. LeClercq, A. Yan, J. E. Homik, and C. A. Dinarello, "Rapid responses to anakinra in patients with refractory adult-onset Still's disease," Arthritis and Rheumatism, vol. 52, no. 6, pp. 1794-1803, 2005.

[306] J. A. Aelion and S. K. Odhav, "Prompt response to treatment with anakinra in adult onset Still's disease," Annals of the Rheumatic Diseases, vol. 63, supplement 1, p. 265, 2004.

[307] B. Haraoui, D. Bourrelle, and E. Kaminska, "Anakinra in the treatment of adult onset Still's disease," Annals of the Rheumatic Diseases, vol. 63, supplement 1, article 263, 2004.

[308] M. Lahiri and G.-G. Teng, "A case of refractory adult-onset Still's disease treated with anakinra," International Journal of Rheumatic Diseases, vol. 13, no. 3, pp. e36-e41, 2010.

[309] G. Moulis, L. Sailler, L. Astudillo, G. Pugnet, and P. Arlet, "May anakinra be used earlier in adult onset Still disease?" Clinical Rheumatology, vol. 29, no. 10, pp. 1199-1200, 2010.

[310] E. Mylona, S. Golfinopoulou, M. Samarkos, P. Fanourgiakis, V. Papadakos, and A. Skoutelis, "Acute hepatitis in adult Still's disease during corticosteroid treatment successfully treated with anakinra," Clinical Rheumatology, vol. 27, no. 5, pp. 659661, 2008.

[311] B. Raffeiner, C. Botsios, C. A. Dinarello, F. Ometto, L. Punzi, and R. Ramonda, "Adult-onset Still's disease with myocarditis successfully treated with the interleukin-1 receptor antagonist anakinra," Joint Bone Spine, vol. 78, no. 1, pp. 100-101, 2011.

[312] A. Rudinskaya and D. H. Trock, "Successful treatment of a patient with refractory Adult-onset Still disease with anakinra," Journal of Clinical Rheumatology, vol. 9, no. 5, pp. 330-332, 2003.

[313] H. Tamaki, H. Shimizu, E. Hiraoka et al., "Marked effect and steroid-sparing ability of anakinra on a patient with refractory adult-onset Still's disease," Modern Rheumatology, vol. 20, no. 2, pp. 200-204, 2010.

[314] F. M. Vasques Godinho, M. J. Parreira Santos, and J. C. da Silva, "Refractory adult onset Still's disease successfully treated with anakinra," Annals of the Rheumatic Diseases, vol. 64, no. 4, pp. 647-648, 2005.

[315] S. Vordenbäumen, B. Ostendorf, O. Sander, J. Richter, and M. Schneider, "Continuation of anakinra despite the development of a pruritic rash in an otherwise refractory case of adult-onset Still's disease," Annals of the Rheumatic Diseases, vol. 68, no. 3, pp. 450-451, 2009.

[316] J. Youssef, E. Lazaro, P. Blanco, and J. F. Viallard, "Blockade of interleukin 1 receptor in still's disease affects activation of peripheral T-lymphocytes," Journal of Rheumatology, vol. 35, no. 12, pp. 2453-2456, 2008.

[317] P. Woo, "Anakinra treatment for systemic juvenile idiopathic arthritis and adult onset Still disease," Annals of the Rheumatic Diseases, vol. 67, no. 3, pp. 281-282, 2008.

[318] Á. Terán, F. Casafont, E. Fábrega, V. M. Martínez-Taboada, V. Rodríguez-Valverde, and F. Pons-Romero, "Adult-onset Still's disease with liver failure requiring liver transplantation," Gastroenterología y Hepatología, vol. 32, no. 10, pp. 681-686, 2009.

[319] C. Rinkin, C. van Durme, B. Fautrel, and M. Malaise, "A rare case of arthritis and fever," Revue Medicale de Liege, vol. 68, no. 7-8, pp. 423-427, 2013. 
[320] C. Iliou, C. Papagoras, N. Tsifetaki, P. V. Voulgari, and A. A. Drosos, "Adult-onset Still's disease: clinical, serological and therapeutic considerations," Clinical and Experimental Rheumatology, vol. 31, no. 1, pp. 47-52, 2013.

[321] N. T. Jaqua, D. Finger, and J. S. Hawley, "Adult-onset Still's disease masquerading as sepsis in an asplenic active duty soldier," Case Reports in Medicine, vol. 2012, Article ID 349521, 3 pages, 2012.

[322] K. Laskari, A. G. Tzioufas, and H. M. Moutsopoulos, "Efficacy and long-term follow-up of IL-1R inhibitor anakinra in adults with Still's disease: a case-series study," Arthritis Research and Therapy, vol. 13, no. 3, article R91, 2011.

[323] D. Nordström, A. Knight, R. Luukkainen et al., "Beneficial effect of interleukin 1 inhibition with anakinra in adult-onset Still's disease. An open, randomized, multicenter study," The Journal of Rheumatology, vol. 39, no. 10, pp. 2008-2011, 2012.

[324] C. Giampietro, M. Ridene, T. Lequerre et al., "Anakinra in adultonset still's disease: long-term treatment in patients resistant to conventional therapy," Arthritis Care and Research, vol. 65, no. 5, pp. 822-826, 2013.

[325] C. Henderson, W. Mildred, T.-H. Pham et al., "Safety and efficacy of IL-1 Trap in resistant adult onset Still's disease: 24 month follow-up of open label treatment and biomarkers of response," Arthritis \& Rheumatology, vol. 62, supplement 10, p. 1831, 2010.

[326] O. Petryna, J. J. Cush, and P. Efthimiou, "IL-1 trap rilonacept in refractory adult onset Still's disease," Annals of the Rheumatic Diseases, vol. 71, no. 12, pp. 2056-2057, 2012.

[327] A. Kontzias and P. Efthimiou, "The use of canakinumab, a novel IL-1 $\beta$ long-acting inhibitor, in refractory adult-onset Still's disease," Seminars in Arthritis and Rheumatism, vol. 42, no. 2, pp. 201-205, 2012.

[328] A. Lo Gullo, A. Caruso, N. Pipitone, P. Macchioni, G. Pazzola, and C. Salvarani, "Canakinumab in a case of adult onset Still's disease: efficacy only on systemic manifestations," Joint Bone Spine, vol. 81, no. 4, pp. 376-377, 2014. 


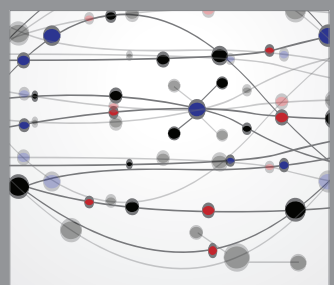

The Scientific World Journal
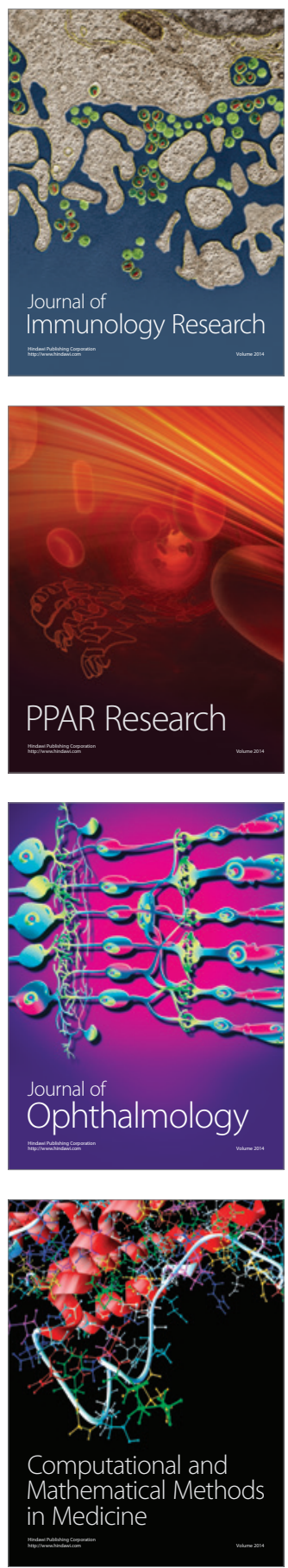

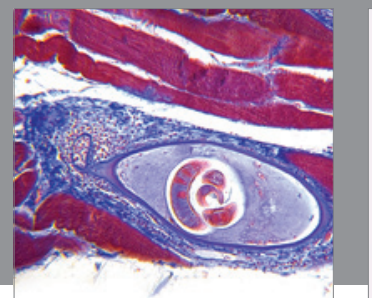

Gastroenterology

Research and Practice
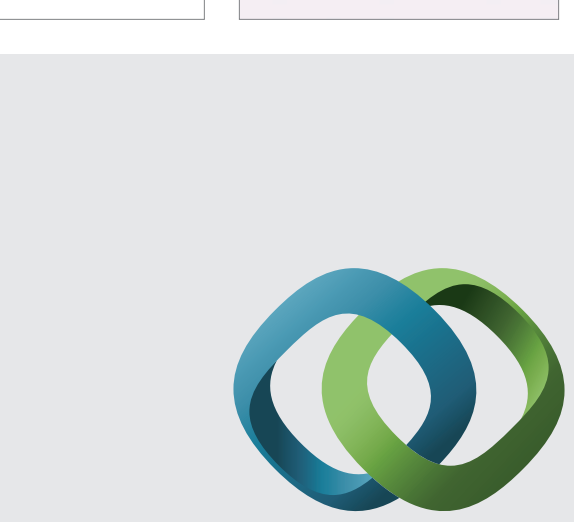

\section{Hindawi}

Submit your manuscripts at

http://www.hindawi.com
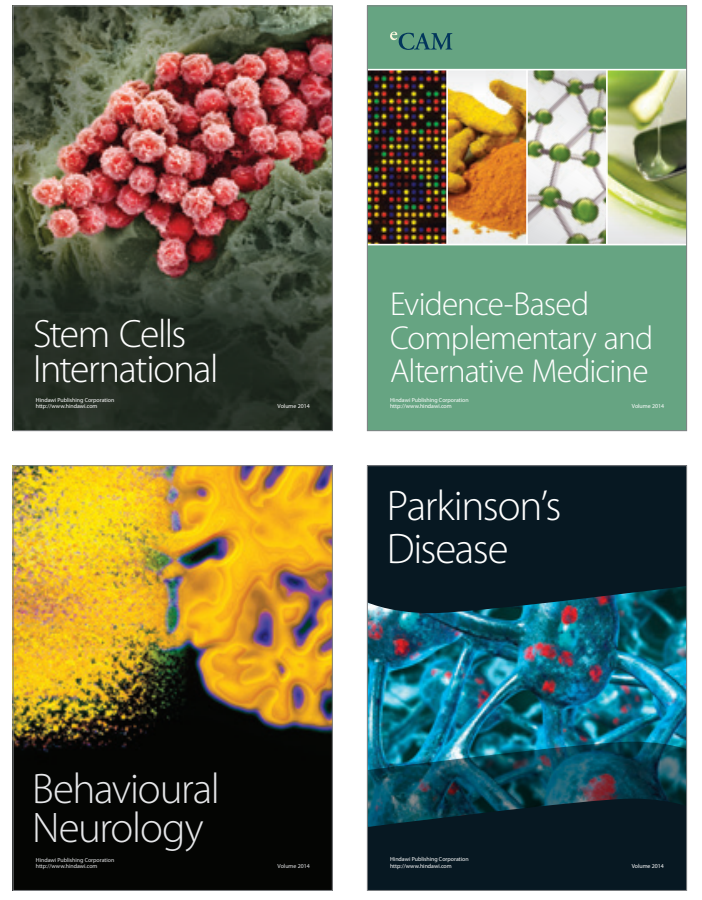
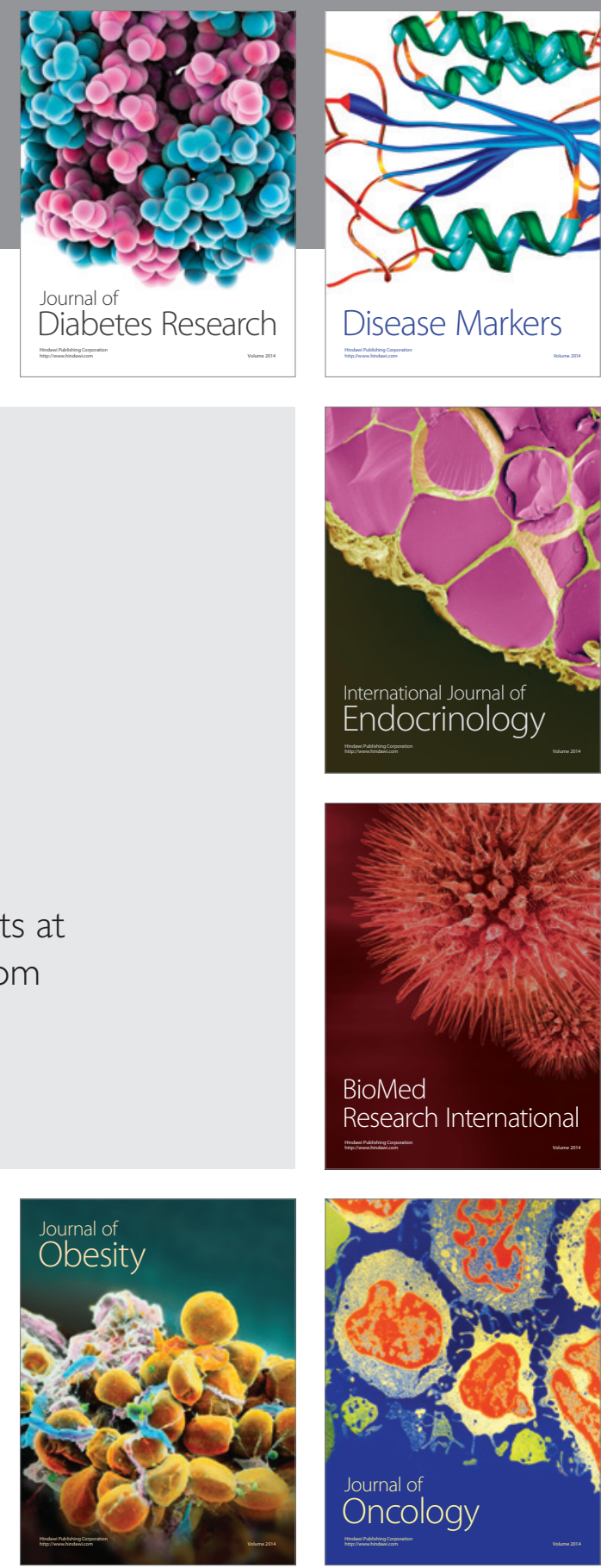

Disease Markers
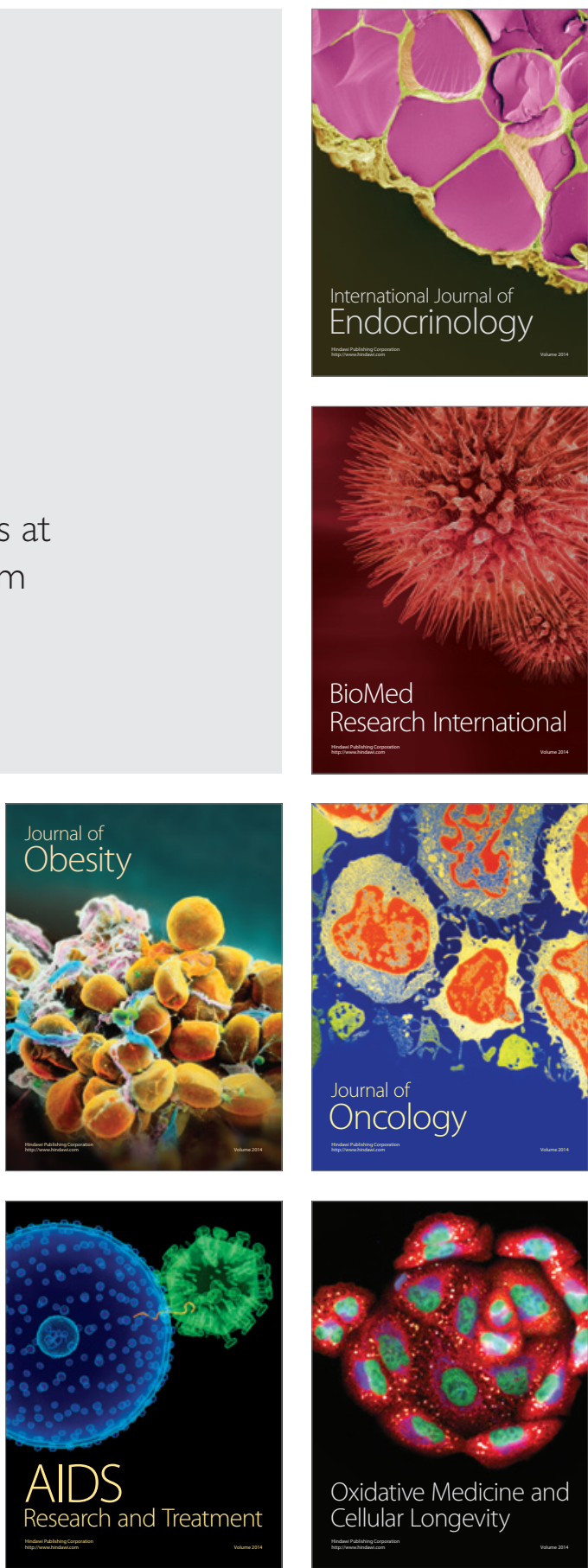